\title{
Chitosan nanoparticles as a modified diclofenac drug release system
}

\author{
Anivaldo Pereira Duarte Junior • Eraldo José Madureira Tavares • \\ Taís Vanessa Gabbay Alves • Márcia Regina de Moura • \\ Carlos Emmerson Ferreira da Costa • José Otávio Carréra Silva Júnior • \\ Roseane Maria Ribeiro Costa
}

Received: 20 January 2017 / Accepted: 13 July 2017 / Published online: 4 August 2017

(C) Springer Science+Business Media B.V. 2017

\begin{abstract}
This study evaluated a modified nanostructured release system employing diclofenac as a drug model. Biodegradable chitosan nanoparticles were prepared with chitosan concentrations between 0.5 and $0.8 \%(w / v)$ by template polymerization method using methacrylic acid in aqueous solution. Chitosanpoly(methacrylic acid) (CS-PMAA) nanoparticles showed uniform size around $50-100 \mathrm{~nm}$, homogeneous morphology, and spherical shape. Raw material and chitosan nanoparticles were characterized by thermal analysis, Fourier transform infrared spectroscopy (FT-
\end{abstract}

\footnotetext{
A. P. Duarte Junior • T. V. G. Alves •

R. M. Ribeiro Costa $(\bowtie)$

Laboratory of Pharmaceutical Nanotechnology, College of Pharmacy, Federal University of Pará, Belém, Pará 66075-110, Brazil

e-mail: rmrc@ufpa.br
}

\begin{abstract}
A. P. Duarte Junior · J. O. C. Silva Júnior
Laboratory R\&D Pharmaceutical and Cosmetic, College of Pharmacy, Federal University of Pará, Belém, Pará 66075-110, Brazil
\end{abstract}

E. J. M. Tavares

Brazilian Agricultural Research Corporation, Eastern Amazon,

Laboratory of Agrobusiness, Belém, Pará 660095-100, Brazil

M. R. de Moura

Faculdade de Engenharia de Ilha Solteira, Departamento de Física e Química, UNESP_-Universidade Estadual Paulista, Ilha Solteira, SP 15385-000, Brazil

C. E. F. da Costa

Faculty of Chemical Engineering, Federal University of Pará, Belém, Pará 66075-110, Brazil
IR), and transmission electron microscopy (TEM), confirming the interaction between chitosan and methacrylic acid during nanoparticles preparation. Diclofenac sorption on the chitosan nanoparticles surface was achieved by incubation in water/ethanol $(1: 1)$ drug solution in concentrations of 0.5 and $0.8 \mathrm{mg} / \mathrm{mL}$. The diclofenac amount sorbed per gram of CS-PMAA nanoparticles, when in a $0.5 \mathrm{mg} / \mathrm{mL}$ sodium diclofenac solution, was as follows: 12.93, 15, 20.87, and $29.63 \mathrm{mg} / \mathrm{g}$ for CS-PMAA nanoparticles $0.5,0.6,0.7$, and $0.8 \%(w / v)$, respectively. When a $0.8 \mathrm{mg} / \mathrm{mL}$ sodium diclofenac solution was used, higher sorption efficiencies were obtained: For CS-PMAA nanoparticles with chitosan concentrations of $0.5,0.6,0.7$, and $0.8 \%$ $(w / v)$, the sorption efficiencies were $33.39,49.58,55.23$, and $67.2 \mathrm{mg} / \mathrm{g}$, respectively. Diclofenac sorption kinetics followed a second-order kinetics. Drug release from nanoparticles occurred in a period of up to $48 \mathrm{~h}$ and obeyed Korsmeyer-Peppas model, which was characterized mainly by Fickian diffusion transport.

Keywords Nanoparticle · Chitosan · Drug delivery · Nanotechnology $\cdot$ Biopolymer Pharmaceutics

\section{Introduction}

Chitosan (CS) is a derivative of chitin, a natural biopolymer present in crustacean shells, insect exoskeletons, and fungi cell walls. Chitin is the second most abundant biopolymer in nature and is often considered a cellulose derivative because it contains a similar 
chemical structure except for acetamide chemical groups (NHCOCH3) present at $\mathrm{C}-2$ carbon position. Despite the similarity, chitin and chitosan are not found in organisms that produce cellulose (Dutta et al. 2004). Chitin is composed of 2-acetamido-2-deoxy- $\beta$-D-glucopyranose homopolymer units joined by (1-4) beta-linkages. When a unit is deacetylated, it results in a beta-(14)-2-amino-2-deoxy-D-glucopyranose structure. If more than $50 \%$ of the glucopyranose residues are deacetylated, the polymer is known as chitosan (Zargar et al. 2015). These amine groups found in chitosan molecular structure become positively charged in acid media $(\mathrm{pH}<6.5)$ and therefore promote biopolymer aqueous solubility (Kumar et al. 2004). Chitin and chitosan chemical structures can be observed in Fig. 1.

There are three types of functional reactive groups in chitosan: one amine group at $\mathrm{C}-2$ position and two hydroxyl groups at C-3 and C-6 positions. These reactive groups can be modified and provide many useful materials in various applications such as antimicrobial agent (Qin et al. 2006), formation of edible films (Elsabee 2015; Hosseini et al. 2015), improvement in controlled drug delivery (Luo et al. 2015), chelating agent for heavy metals (Yu et al. 2013; Bratskaya et al. 2009), and other applications in nutritional, health, and environmental fields (Shahidi et al. 1999; Sorrentino et al. 2007). The amine functional group has a basic character and therefore reacts with acids such as poly(methacrylic acid) (PMAA), resulting in copolymer chitosan-(poly)methacrylic acid (CS-PMAA) formation (De Moura et al. 2008; Fang et al. 1999).

The interaction between chitosan amine groups and methacrylic acid carboxylic groups occurs during methacrylic acid polymerization with chitosan as

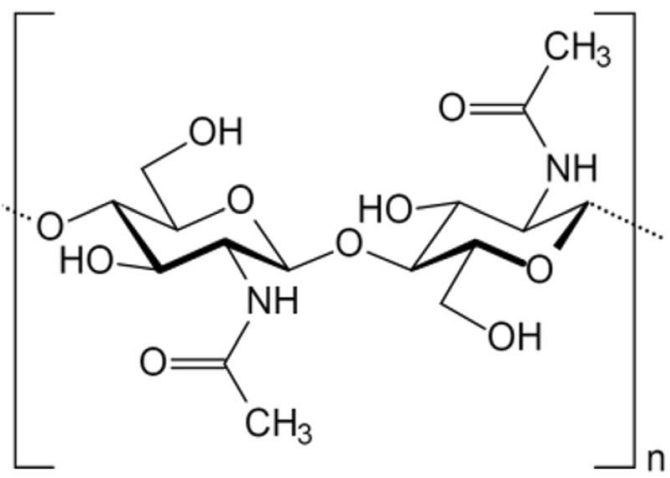

Chitin template. This method of nanoparticles preparation is called type II template polymerization mechanism (Połowiński 2002; Hu et al. 2002; Ahn et al. 2001; Kozhunova et al. 2015; Akashi and Ajiro 2015). The advantage of this method is the absence of organic solvents and surfactants during the preparation of nanoparticles, increasing safety and biocompatibility. Nanoparticles obtained by template polymerization method have an increased biocompatibility in comparison with those obtained by other methods that use organic solvents (Gong et al. 2014). The method has applications in several areas (Zhang et al. 2014; Gong et al. 2014; Wen et al. 2014).

Chitosan nanoparticles have characteristics like $\mathrm{pH}$ sensitivity, biocompatibility, and low toxicity, making them a promising candidate for new controlled release drug systems development. An interesting chitosan nanoparticles feature is the possibility to carry hydrophilic drugs such as peptides and proteins due to their hydrophilic character (Piras et al. 2015; Poth et al. 2015; Hecq et al. 2015). Another relevant characteristic is the positively charged chitosan nanoparticle surface, which promotes electrostatic interaction with biological membranes that are negatively charged and improvement in nanoparticle stability in the presence of biological cations (Agnihotri et al. 2004; Laranjeira and Fávere 2009).

Nanotechnology-based drug delivery systems can present a modified release profile, and the use of chitosan in these systems has advantages such as mucoadhesive properties, which facilitates drug penetration (Issa et al. 2005). For this reason, diclofenac is a good candidate for sustained release due to its short biological half-life and its provoking adverse gastrointestinal reaction. When the drug is sorbed in

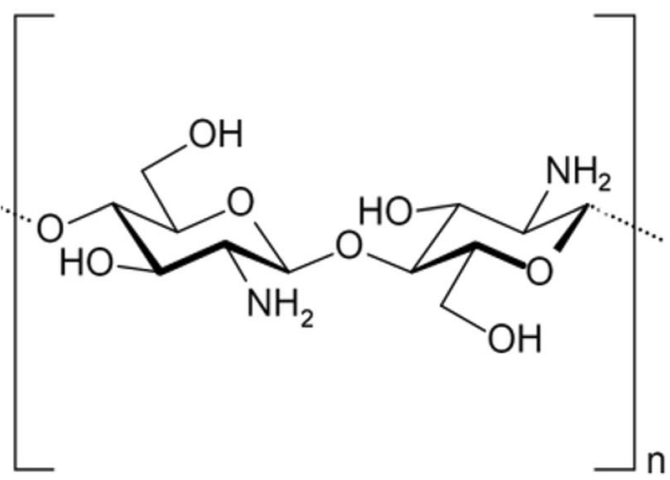

Chitosan

Fig. 1 Chitin (2-acetamido-2-deoxy- $\beta$-D-glucopyranose) and chitosan (beta-(1-4)-2-amino-2-deoxy-D-glucopyranose) chemical structures (Younes and Rinaudo 2015) 
nanoparticles, the drug blood level can be modulated to oscillate in lower amplitude and frequency, decreasing toxicity and increasing both efficiency and patient compliance (Manjanna et al. 2009). Previous studies indicate that CS-PMAA nanoparticles can be obtained in various sizes and show different surface charge properties according to environmental pH (De Moura et al. 2008).

The objective of this study was to evaluate CSPMAA nanoparticles as a modified drug release system for diclofenac, investigate thermal stability by differential scanning calorimetry (DSC) and thermogravimetric analysis (TGA) and characterize them with Fourier transform infrared spectroscopy (FT-IR) and transmission electron microscopy (TEM).

\section{Material and methods}

Materials

Chitosan (MW = $71.3 \mathrm{kDa}$, deacetylation degree 94\%) was a gift from Polymar Science and Nutrition S/A (Fortaleza, Brazil). Potassium persulfate $\left(\mathrm{K}_{2} \mathrm{~S}_{2} \mathrm{O}_{8}\right)$ analytical grade was purchased from Synth LTDA (São Paulo, Brazil), and sodium diclofenac and methacrylic acid (MAA) were purchased from Sigma-Aldrich (St. Louis, USA). All reagents were used as received.

\section{CS-PMAA nanoparticles preparation}

CS-PMAA nanoparticles were obtained according to methodology used by De Moura et al. (2008), which consists of methacrylic acid polymerization using chitosan as a template. Chitosan in different concentrations $(0.5,0.6,0.7$, and $0.8 \%(w / v))$ was dissolved in a MAA aqueous solution $0.5 \%(\mathrm{v} / \mathrm{v})$ for $12 \mathrm{~h}$ under magnetic stirring at room temperature. Chitosan completely dissolved in MAA solution was warmed up to $70{ }^{\circ} \mathrm{C}$, and then $5 \mathrm{~mL}$ of $0.2 \mathrm{~mol} \mathrm{~K}_{2} \mathrm{~S}_{2} \mathrm{O}_{8}$ aqueous solution was added. The warmed solution was kept under magnetic stirring for $1 \mathrm{~h}$, resulting in CS-PMAA nanoparticles formation. After obtaining CS-PMAA nanoparticles, the dispersion was cooled in an ice bath until reaching ambient temperature. Finally, the CS-PMAA nanoparticles dispersion was kept in refrigerator at $-20{ }^{\circ} \mathrm{C}$ for $24 \mathrm{~h}$ and then was lyophilized using a freeze dryer LIOBRAS model Liotop L-101 (São Carlos, Brazil) for $12 \mathrm{~h}$.
Transmission electron microscopy (TEM)

TEM images were obtained in a transmission electron microscope ZEISS, model EM 90 (Oberkochen, Germany). First, a phosphotungstic acid solution at $2 \%$ $(w / v)$ and $\mathrm{pH} 3$ was prepared. Then CS-PMAA nanoparticles dispersion was sonicated for $10 \mathrm{~min}$, and an aliquot of $10 \mu \mathrm{L}$ was placed in a FORMVAR grid coated with carbon. After a 30-s contact of CS-PMAA nanoparticles and FORMVAR grid, the excess was removed with filter paper. Later, $10 \mu \mathrm{L}$ of a previously prepared fototungstic acid solution was added, and the excess was removed from grid after $30 \mathrm{~s}$ with filter paper. Grids were dried at room temperature and then visualized by TEM operated at $80 \mathrm{kV}$.

FT-IR analysis

Freeze-dried CS-PMAA nanoparticles and pure chitosan samples were mixed with potassium bromide $(\mathrm{KBr})$ and pressed at high pressure to form pellets. FT-IR spectra were obtained by recording 64 scans in the range from 4000 to $400 \mathrm{~cm}^{-1}$ and $4 \mathrm{~cm}^{-1}$ resolution in a Perkin-Elmer FT-IR spectrometer model $1760 \mathrm{X}$ (Waltham, USA).

Thermal analysis

Pure chitosan and samples containing CS-PMAA nanoparticles $0.5,0.6,0.7$, and $0.8 \%(w / v)$ were submitted to thermal analysis. Thermogravimetric and derivative thermogravimetric curves (TG-DTG) were carried out in thermobalance Shimadzu DTG-60H (Kyoto, Japan). The samples $(2.5 \pm 0.5 \mathrm{mg})$ were placed in open alumina crucibles and subjected to a temperature up to $600{ }^{\circ} \mathrm{C}$ at 5 and $10{ }^{\circ} \mathrm{C} / \mathrm{min}$ heating rates under dynamic nitrogen atmosphere $(50 \mathrm{~mL} / \mathrm{min}$ flow rate).

DSC curves were performed on a Shimadzu thermal analyzer, model DSC 60 (Kyoto, Japan). The samples $(2.5 \pm 0.5 \mathrm{mg})$ were placed in closed aluminum crucibles and subjected to temperature up to $450{ }^{\circ} \mathrm{C}$ under dynamic nitrogen atmosphere $(50 \mathrm{~mL} / \mathrm{min}$ flow rate) and heating rates of 5 and $10{ }^{\circ} \mathrm{C} / \mathrm{min}$. Equipment calibration was performed using indium as standard.

Diclofenac sorption on the CS-PMAA nanoparticles

Diclofenac sorption on the CS-PMAA nanoparticles was performed by incubation. First, a water/ethanol (1:1) diclofenac sodium solution $(0.5$ and $0.8 \mathrm{mg} / \mathrm{mL})$ 
at $\mathrm{pH} 5.5$ was prepared. Then, $0.5,0.6,0.7$, and $0.8 \%$ $(w / v)$ lyophilized CS-PMAA nanoparticles were added in proportion (1:200) to different concentrations of diclofenac sodium solutions at room temperature and under constant magnetic stirring.

After reaching equilibrium, CS-PMAA nanoparticles were separated from diclofenac sodium solution by ultrafiltration/centrifugation process through $30 \mathrm{KDa}$ pore size Microcon-Millipore (Bedford, USA) centrifugal filter devices for $30 \mathrm{~min}$ at $3000 \mathrm{RPM}$.

\section{Diclofenac sorption efficiency on the CS-PMAA} nanoparticles

Sorption efficiency was calculated through the quantification of the drug present in the incubation media supernatant obtained after ultrafiltration process by UVVis spectrophotometer at $280 \mathrm{~nm}$ wavelength (Hu et al. 2002; Yuan et al. 2010; Bayramoglu et al. 2002). The sorption efficiency $(E f)$, expressed as the amount of sorbed drug in milligrams per gram of CS-PMAA nanoparticles, was calculated through:

$E f=\left(\frac{C i-C f}{m}\right) \times 1000$

where $E f(\mathrm{mg} / \mathrm{g})$ is drug amount contained in CS-PMAA nanoparticles, $C i$ and $C f(\mathrm{mg} / \mathrm{mL})$ are diclofenac concentrations in the beginning and after the experiment at a given time, respectively, and $m$ is CS-PMAA nanoparticles concentration $(\mathrm{mg} / \mathrm{mL})$ added to incubation medium. Diclofenac sorption efficiency on CS-PMAA nanoparticles was evaluated through contact time between diclofenac and CS-PMAA nanoparticles as well as diclofenac sodium solution concentration. Sorption mechanism concerning kinetic order process and kinetic rate constant was evaluated by first- and second-order models. The integrated rate equations used are shown in Eqs. 2 and 3, which correspond to pseudo-first-order and pseudo-second-order kinetics models, respectively (Patil et al. 2011; Ho 2006; Ho and McKay 1999).

$$
\begin{aligned}
& \log \left(Q_{e}-Q_{t}\right)=\log Q_{e}-\left(\frac{k_{1}}{2.303}\right) \times t \\
& \frac{t}{Q_{t}}=\frac{1}{k_{2} Q_{e}^{2}}+\frac{1}{Q_{e}} \times t
\end{aligned}
$$

Qe values correspond to drug amount contained in CS-PMAA nanoparticles at equilibrium (mg/g), Qt corresponds to drug amount sorbed $(\mathrm{mg} / \mathrm{g})$ at time $t(\mathrm{~min})$,
$K_{l}\left(\min ^{-1}\right)$, and $K_{2}\left(\mathrm{~g} \cdot \mathrm{mg}^{-1} \cdot \mathrm{min}^{-1}\right)$ are pseudo-first and pseudo-second-order reactions constant rates, respectively. Diclofenac sorption in CS-PMAA nanoparticles was described plotting $\log (Q e-Q t)$ versus $t$ for pseudofirst-order equation and $t / Q t$ versus $t$ for pseudo-secondorder equation. $K_{1}$ and $K_{2}$ constants were, respectively, calculated from the slope and intercept of the straight lines from the graphics obtained. The highest correlation coefficient $\left(r^{2}\right)$ obtained from regression analysis demonstrated best fitted kinetics model.

In vitro release of diclofenac from the CS-PMAA nanoparticles

In vitro release assays were conducted using a twocompartment system to observe diclofenac release from loaded CS-PMAA nanoparticles. Dialysis device SpectraPor Float-A-Lyzer G2 (Houston, USA) with $20 \mathrm{kDa}$ molecular exclusion pore and $10 \mathrm{~mL}$ capacity was used. This device was placed in contact with $50 \mathrm{~mL}$ phosphate-buffered saline ( $\mathrm{pH}$ 7.4) in a test tube (acceptor compartment) under mild magnetic stirring and constant temperature of $37 \pm 0.5^{\circ} \mathrm{C}$ (Berthold et al. 1996; Paavola et al. 1995). A sample of drug-loaded CSPMAA nanoparticles was first dispersed in $5 \mathrm{~mL}$ phosphate-buffered saline ( $\mathrm{pH}$ 7.4) and added to the dialysis device, which was then immersed in a tube with $45 \mathrm{~mL}$ phosphate-buffered saline $(\mathrm{pH} 7.4)$ and maintained under constant stirring at $37 \pm 0.5^{\circ} \mathrm{C}$. The experiment was performed under sink conditions. Samples were collected from the acceptor compartment at $0.5,1$, $2,4,8,24$, and $48 \mathrm{~h}$ after initiation of the assay and quantified by UV-Vis spectrophotometry $(280 \mathrm{~nm})$.

After each sample collection, an equal amount of fresh phosphate-buffered saline, $\mathrm{pH}$ 7.4, was returned to the system. The Korsmeyer-Peppas release kinetic model was used to describe the release behavior of diclofenac from CS-PMAA nanoparticles. This model correlates drug release versus time by a single exponential equation, described by:

$$
\left(\frac{M t}{M \infty}\right)=k \times t^{n}
$$

where $M_{t}$ and $M \infty$ are the amount of drug released at a given time $t$ and at infinite time, respectively; $k$ is a constant and $n$ is the release exponent (Sinclair and Peppas 1984). The value of $n$ is related to the release mechanism and can vary with polymer type, particle 
shape, size, polydispersivity, and the shape of size distribution (Ritger and Peppas 1987). The glass transition temperature ( $\mathrm{Tg}$ ) of chitosan is $203{ }^{\circ} \mathrm{C}$ (Sakurai et al. 2000), so the dry nanoparticles are in glassy state at room temperature. Chitosan nanoparticles swell moderately in slightly acidic water solution (Yuan et al. 2010). Limiting values of exponent $n$ are 0.432 , for pure Fickian release, and 0.85 , for case II transport, when the drug is released from the swelling-controlled release system, formed by monodispersed, spherical particles made of hydrophilic, and initially glassy polymer. However, when these spheres present size distribution, no limits are set since $n$ value will vary with shape and breadth of distribution. In this case, the limiting values of $n$ can be much lower (ex., 0.3 for Fickian diffusion and 0.45 for case II transport (Ritger and Peppas 1987).

The value of $n$ was determined by taking the logarithms to base 10 of both sides of Eq. 5 and applying laws of logarithms,

$\log \frac{M_{\mathrm{t}}}{M_{\infty}}=\log k+n \cdot \log t$

where $n$ is the slope (Sinclair and Peppas 1984).

\section{Results and discussion}

Nanoparticles preparation

CS-PMAA nanoparticles preparation was carried out by template polymerization method, in which monomeric units are arranged by a pre-formed macromolecule (template) solubilized in the same solvent (De Moura et al. 2008; Połowiński 2002). CS has positive polyelectrolyte characteristics in acidic solution, whereas the methacrylic acid has negative ones. A micelle-like structure is formed before the polymerization begins, which suggests that interaction between CS and the acid is promoted by electrostatic interactions among protonated groups of CS and deprotonated MAA monomers. The electrostatic interaction and subsequent methacrylic acid polymerization promote the formation of CS-PMAA nanoparticles (Hu et al. 2005; Połowiński 2002). Template polymerization method has been used successfully for CS-PMAA nanoparticles preparation. In a template polymerization, the polymerization and the polymertemplate interaction should occur simultaneously. The process is an easy and efficient method for obtaining nanoparticles (Wang et al. 2009).

\section{FT-IR analysis}

Table 1 shows FT-IR absorption bands and their functional groups related to pure CS.

Pure CS FT-IR spectra shows characteristic absorption peaks at $1649 \mathrm{~cm}^{-1}$, corresponding to primary amide $\mathrm{C}=\mathrm{O}$ bond stretching vibrations, between 1083 and $1020 \mathrm{~cm}^{-1}$ related to $\mathrm{C}-\mathrm{O}$ stretch, and at $620 \mathrm{~cm}^{-1}$ due to pyranoside rings vibrations (Bhumkar and Pokharkar 2006; De Moura et al. 2008).

In CS composition, there is always a residual chitin fraction; hence, the presence of primary amide carbonyl group has been detected in FT-IR spectra. This chemical group is located in the absorption band between 1300 and $1700 \mathrm{~cm}^{-1}$, with peak performing at $1649 \mathrm{~cm}^{-1}$, and is usually investigated to determine the CS deacetylation degree (Lima and Airoldi 2004; Monteiro and Airoldi 1999).

The absorption band between 3440 and $3480 \mathrm{~cm}^{-1}$ corresponds to $\mathrm{O}-\mathrm{H}$ axial bond stretching vibration and also NH stretch (Dos Santos et al. 2003). The peaks at 2924 and $2881 \mathrm{~cm}^{-1}$ correspond to $\mathrm{C}-\mathrm{H}$ stretch, to primary amine $\mathrm{N}-\mathrm{H}$ deformation vibrations at $1537 \mathrm{~cm}^{-1}$, to the $\mathrm{C}-\mathrm{H}$ vibration of remaining acetamide $\mathrm{CH} 3$ group at $1375 \mathrm{~cm}^{-1}$, and is related to primary alcohol C-O stretch at $1086 \mathrm{~cm}^{-1}$ (Hellen et al. 2007).

The $\mathrm{O}-\mathrm{H}$ absorption bands of polysaccharides and water molecules appeared near $1640 \mathrm{~cm}^{-1}$, thus making the analysis in this area very complex as it includes the absorbance by both CS amine I and II groups. An increment in CS water content level causes an increase

Table 1 Pure CS FT-IR absorption bands

\begin{tabular}{cl}
\hline Absorption bands $\left(\mathrm{cm}^{-1}\right)$ & Functional group \\
\hline 1649 & $\mathrm{C}=\mathrm{O}$ \\
$1083-1020$ & $\mathrm{C}-\mathrm{O}$ \\
620 & Pyranoside rings \\
3437 & $\mathrm{O}-\mathrm{H}$ \\
2924 and 2881 & $\mathrm{C}-\mathrm{H}$ \\
1537 & $\mathrm{~N}-\mathrm{H}$ \\
1375 & $\mathrm{CH}$ \\
1086 & $\mathrm{C}-\mathrm{O}$ \\
\hline
\end{tabular}


in the absorption band intensity at 1640 and $3450 \mathrm{~cm}^{-1}$. An additional difficulty is imposed by the $\mathrm{NH}_{2}$ group band near $1590 \mathrm{~cm}^{-1}$, which is large enough to interfere with the absorbance near $1655 \mathrm{~cm}^{-1}$ and also influences the absorption at $1560 \mathrm{~cm}^{-1}$ (Shigemasa et al. 1996).

Table 2 shows FT-IR absorption regions and their functional groups related to CS-PMAA nanoparticles. The absorption band at $1638 \mathrm{~cm}^{-1}$ is related to carboxylate ion of methacrylic acid (COO-) and at $1545 \mathrm{~cm}^{-1}$ to $\mathrm{CS}$ protonated amine $(\mathrm{NH} 3+)$ group. The absorption band at $1703 \mathrm{~cm}^{-1}$ assigned to carbonyl group $(\mathrm{C}=\mathrm{O})$ confirms the polymerization of methacrylic acid and the formation of PMAA through $\mathrm{C}=\mathrm{O}$ bonds (Azhgozhinova et al. 2004).

It was observed in FT-IR spectra obtained from CSPMAA nanoparticles (Fig. 2) that the absorption band at $1649 \mathrm{~cm}^{-1}$ found in pure CS spectra related to $\mathrm{C}=\mathrm{O}$ group reduces to two emerging new bands at $1638 \mathrm{~cm}^{-1}$ $\left(\mathrm{COO}^{-}\right)$and $1545 \mathrm{~cm}^{-1}(\mathrm{NH} 3)$, indicating that there was CS-PMAA nanoparticle formation through ionic interaction between the groups CS amine and PMAA carboxylic acid.

Transmission electron microscopy (TEM)

CS-PMAA nanoparticles visualized by TEM showed uniform size, homogeneous morphology, and spherical shape, according to Fig. 3. In TEM images, one can observe that nanoparticles presented some degree of agglomeration, needing refinement by additional formulation optimization. The CS-PMAA nanoparticles shown in Fig. 3 were dispersed in acid medium $(\mathrm{pH} 3)$, with positive surface charge, favoring repulsion between them.

TG-DTG and DSC curves of pure CS and of CS-PMAA nanoparticles

Pure CS TG-DTG curves and thermal decomposition events are illustrated in Fig. 4 and Table 3, respectively.

Table 2 CS-PMAA nanoparticles FT-IR absorption bands

\begin{tabular}{cl}
\hline Absorption bands $\left(\mathrm{cm}^{-1}\right)$ & Functional group \\
\hline 1638 & $\mathrm{COO}^{-}$ \\
1545 & $\mathrm{NH}_{3}^{+}$ \\
1703 & $\mathrm{C}=\mathrm{O}$ \\
\hline
\end{tabular}

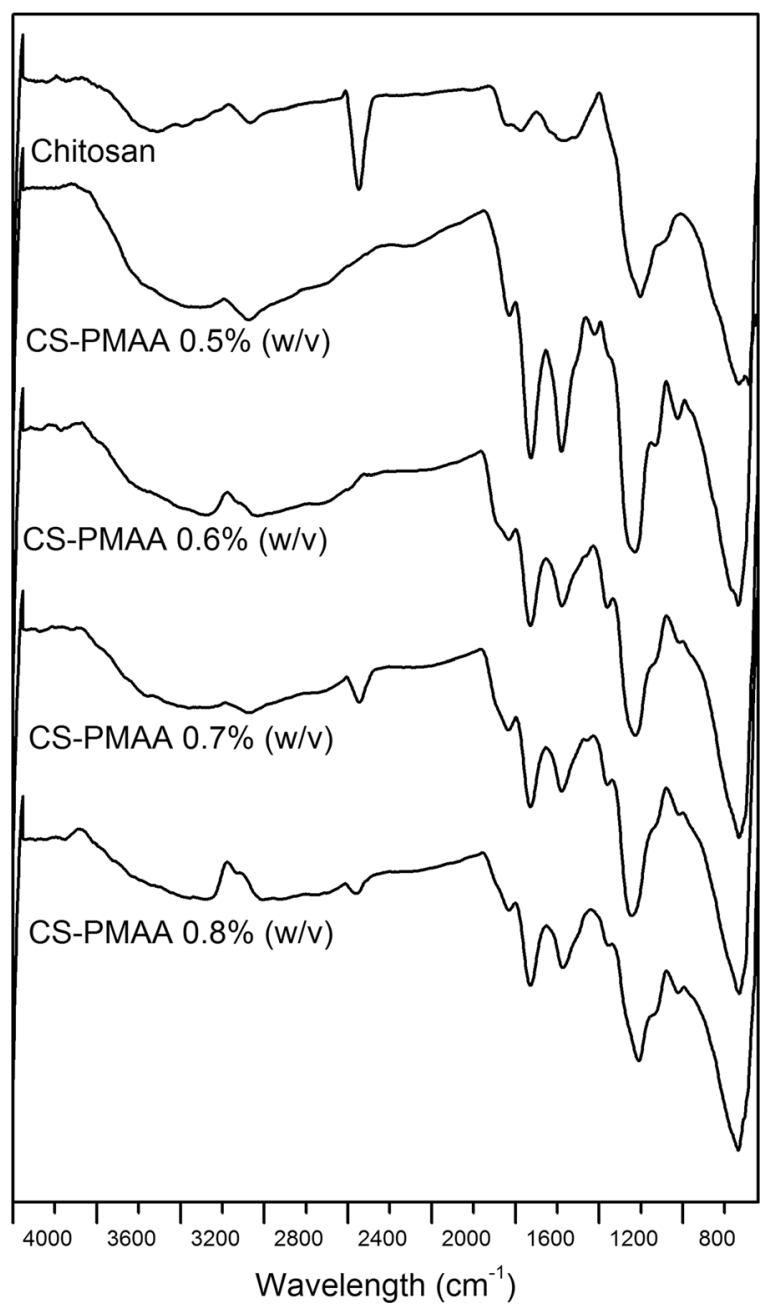

Fig. 2 Pure CS and CS-PMAA nanoparticles FT-IR spectra

In Fig. 4, in a heating rate of $10{ }^{\circ} \mathrm{C} / \mathrm{min}$, mass loss can be identified in two stages: the first, in the range between 25 and $98{ }^{\circ} \mathrm{C}$ with mass loss of approximately $9 \%$ and the second in the range between 216 and $399{ }^{\circ} \mathrm{C}$ with mass loss of $53.37 \%$. The DTG curve peak, where mass loss occurred with greater intensity, was at $45^{\circ} \mathrm{C}$ for the first event and $300{ }^{\circ} \mathrm{C}$ for the second. For the heating rate of $5{ }^{\circ} \mathrm{C} / \mathrm{min}$, the first stage occurred between 25 and $100{ }^{\circ} \mathrm{C}$ with about $13.29 \%$ mass loss and the second in the range between 207 and $382{ }^{\circ} \mathrm{C}$ with $61.83 \%$ mass loss. The DTG curve peak was at $45{ }^{\circ} \mathrm{C}$ for the first event and at $286{ }^{\circ} \mathrm{C}$ for the second. The results found in pure CS TG curves are similar to those found by other studies, in which there was sample weight loss in two stages, with similar degradation temperatures (Tirkistani 1998; Wanjun et al. 2005). 
Fig. 3 Transmission electron microscopy of CS-PMAA nanoparticles $0.5,0.6,0.7$, and $0.8 \%(w / v)$

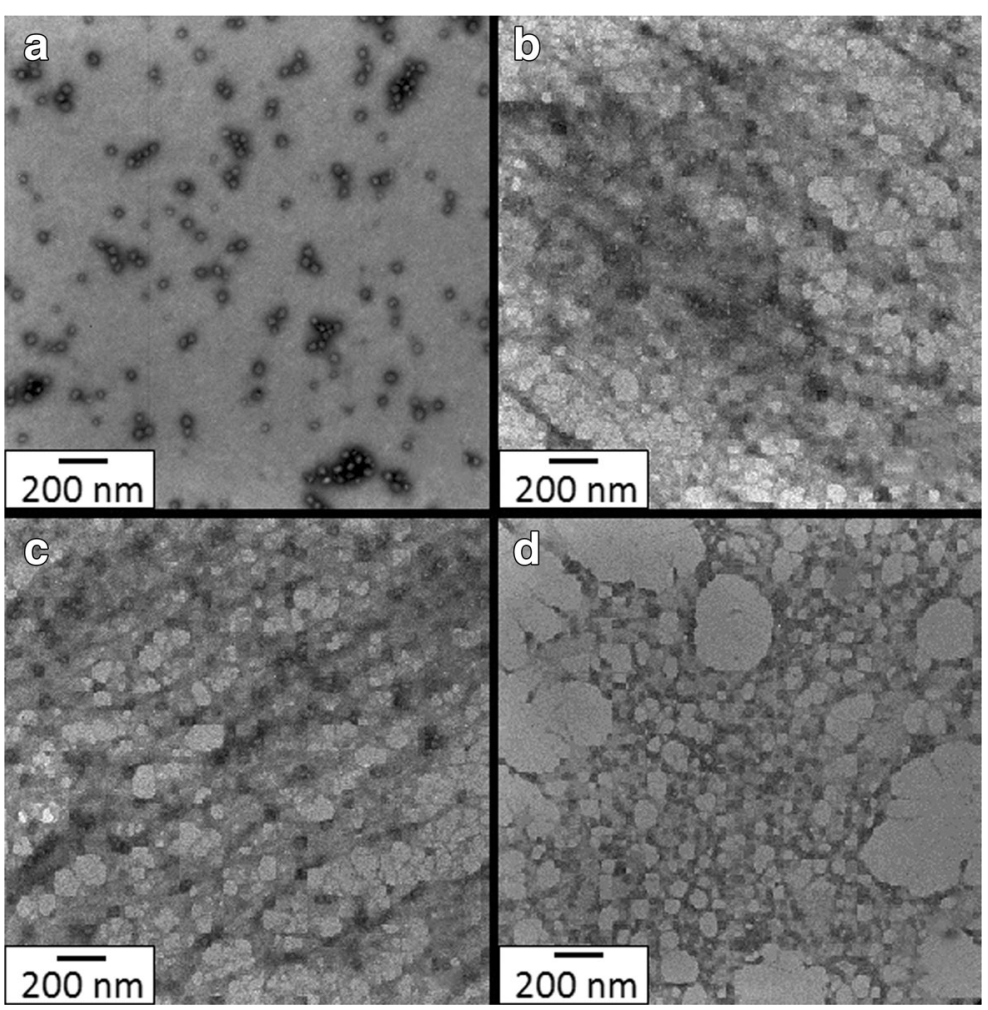

of glycosidic linkages (Nieto et al. 1991; Neto et al. 2005).

Heating rate can affect the thermogravimetric curve profile. When different heating rates are used in the same sample, it is observed that the temperature range
Fig. 4 Pure CS TG-DTG curves in $\mathrm{N}_{2}$ atmosphere $(50 \mathrm{~mL} / \mathrm{min})$ and heating rate at 5 and $10{ }^{\circ} \mathrm{C} / \mathrm{min}$

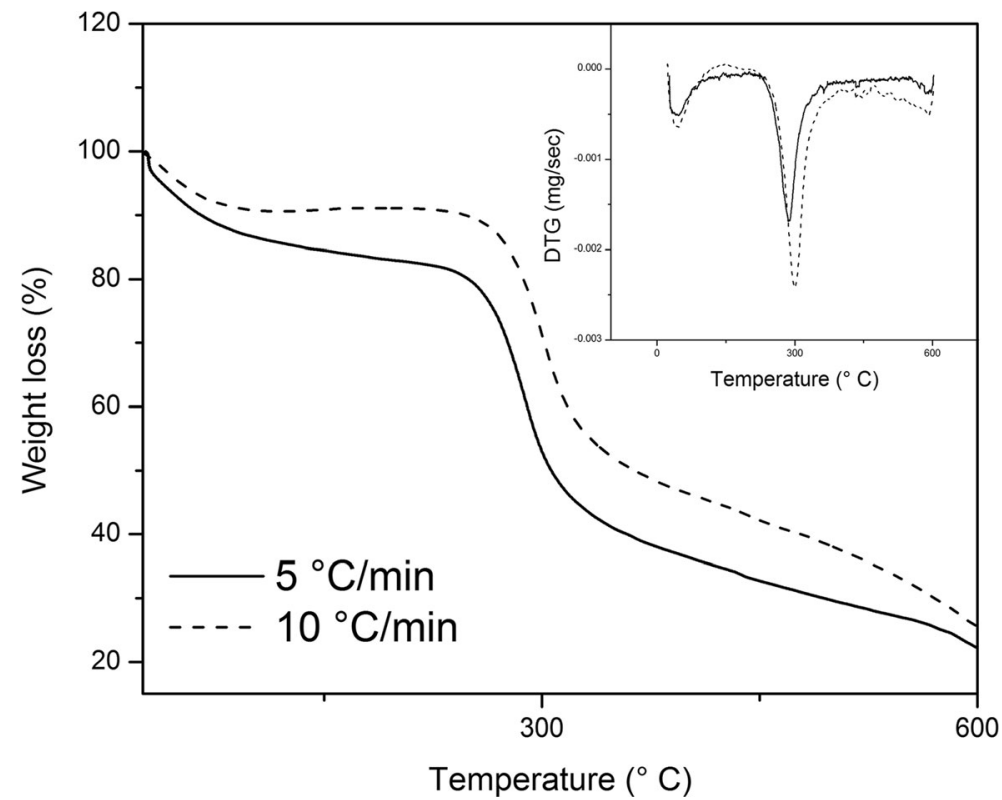


Table 3 Thermal events observed in pure chitosan TG-DTG curves at 5 and $10{ }^{\circ} \mathrm{C} / \mathrm{min}$ heating rates

\begin{tabular}{|c|c|c|c|c|c|c|}
\hline & \multicolumn{3}{|l|}{ First thermal event } & \multicolumn{3}{|c|}{ Second thermal event } \\
\hline & Temperature $\left({ }^{\circ} \mathrm{C}\right)$ & Mass loss $(\%)$ & DTG peak $\left({ }^{\circ} \mathrm{C}\right)$ & Temperature $\left({ }^{\circ} \mathrm{C}\right)$ & Mass loss $(\%)$ & DTG peak $\left({ }^{\circ} \mathrm{C}\right)$ \\
\hline $5^{\circ} \mathrm{C} / \mathrm{min}$ & $25-100$ & 13.29 & 45 & $207-382$ & 61.83 & 286 \\
\hline $10{ }^{\circ} \mathrm{C} / \mathrm{min}$ & $25-98$ & 9 & 45 & $216-399$ & 53.37 & 300 \\
\hline
\end{tabular}

at which thermal events occur undergoes a change: When a higher heating rate is used, the thermal event tends to appear at higher temperature (Cavalheiro et al. 1995).

There were no changes in temperature at which thermal events occurred between 5 and $10{ }^{\circ} \mathrm{C}$ heating rates. What happened was a variation in the speed at which the equipment detected mass variation. Each thermal event occurs at a certain temperature, but due to the faster heating rate, the mass variation caused by the event is only detected at a higher temperature than that at which the event occurred. Other factors that can cause event temperature changes in TG curves are the mass of the sample and gas flow. Therefore, care was taken to perform all TG analysis with constant mass of $2.5 \pm 0.5 \mathrm{mg}$ and $50 \mathrm{~mL} / \mathrm{min} \mathrm{N}_{2}$ gas flow. Small sample mass promotes faster temperature homogenization and thus faster detector response. Slow gas flow rate may cause an insufficient removal of sample volatile products and therefore a delay in the onset temperature of the thermal events (Cavalheiro et al. 1995).

TG-DTG curves of CS-PMAA nanoparticles 0.5 , $0.6,0.7$, and $0.8 \%(w / v)$ at different heating rates are illustrated in Figs. 5, 6, 7, and 8. Also, temperature intervals and peaks of TG-DTG curves of CS-PMAA nanoparticles are summarized in Table 4.

According to Table 4, it was observed that in all TGDTG curves, thermal decomposition occurred in two stages. The first stage of CS-PMAA nanoparticles degradation is achieved by the loss of volatile substances, and the second stage is related to electrostatic interactions lost between CS amine groups and methacrylic acid carboxylic groups as well as the pyrolysis of CS and methacrylic acid polymer chains, providing a series of overlapping reactions. PMAA depolymerization and thermal decomposition products are anhydrides at low temperature and unsaturated chains which have suffered decarboxylation at high temperatures, resulting in small hydrocarbon chains with carboxylic group residues (Moldoveanu 1998; Stoliarov et al. 2004).
According to Fig. 9, CS-PMAA nanoparticles were less thermally stable than pure CS. Pure CS and CSPMAA nanoparticles TG curves at different heating rates $\left(5\right.$ and $\left.10{ }^{\circ} \mathrm{C} / \mathrm{min}\right)$ show that onset temperatures were decreased for all CS-PMAA nanoparticles compared with pure CS.

Decrease in CS-PMAA nanoparticles thermal stability compared with pure CS probably occurred due to the relatively poor thermal stability of PMAA. Thus, some papers reported that PMAA-based nanocomposites exhibited enhanced thermal stability, but the opposite occurred with CS-PMAA nanoparticles (Chrissafis and Bikiaris 2011; De Moura et al. 2008; Friederich et al. 2010; Liaw et al. 2007).

Even with lower thermal stability, CS-PMAA nanoparticles are compatible with the intended use of development of controlled release systems. In fact, at temperatures up to $50^{\circ} \mathrm{C}$, there is a mild difference between CS-PMAA and CS and should have little effect in nanoparticles properties over time. Furthermore, PMAA is crosslinked with CS and changes in PMAA concentration are expected to affect crosslink concentrations and release kinetics properties of CS-PMAA nanoparticles (De Moura et al. 2008).

DSC curves of pure CS and of CS-PMAA nanoparticles $0.5 \%(\mathrm{w} / \mathrm{v})$ at 5 and $10{ }^{\circ} \mathrm{C} / \mathrm{min}$ heating rates are illustrated in Fig. 10a, b. In pure CS DSC curve at heating rate of $5{ }^{\circ} \mathrm{C} / \mathrm{min}$, an endothermic peak can be found near $80{ }^{\circ} \mathrm{C}$ attributed to evaporation of volatile substances such as water molecules linked through hydrogen bonds with CS hydroxyl and amine groups. Another thermal event found was an exothermic peak near $285^{\circ} \mathrm{C}$, corresponding to $\mathrm{CS}$ degradation.

The same events occurred at heating rate of $10{ }^{\circ} \mathrm{C} /$ $\mathrm{min}$, but the endothermic event attributed to evaporation of volatiles presented a more intense peak and occurred at a higher temperature, around $100{ }^{\circ} \mathrm{C}$. The exothermic peak corresponding to CS degradation was also more intense and, at a higher temperature, around $300{ }^{\circ} \mathrm{C}$. The use of higher heating rates causes DSC peaks 
Fig. 5 CS-PMAA nanoparticles $0.5 \%(w / v)$ TG-DTG curves obtained in $\mathrm{N}_{2}$ atmosphere $(50 \mathrm{~mL} / \mathrm{min})$ and heating rating at 10 and $5^{\circ} \mathrm{C} / \mathrm{min}$

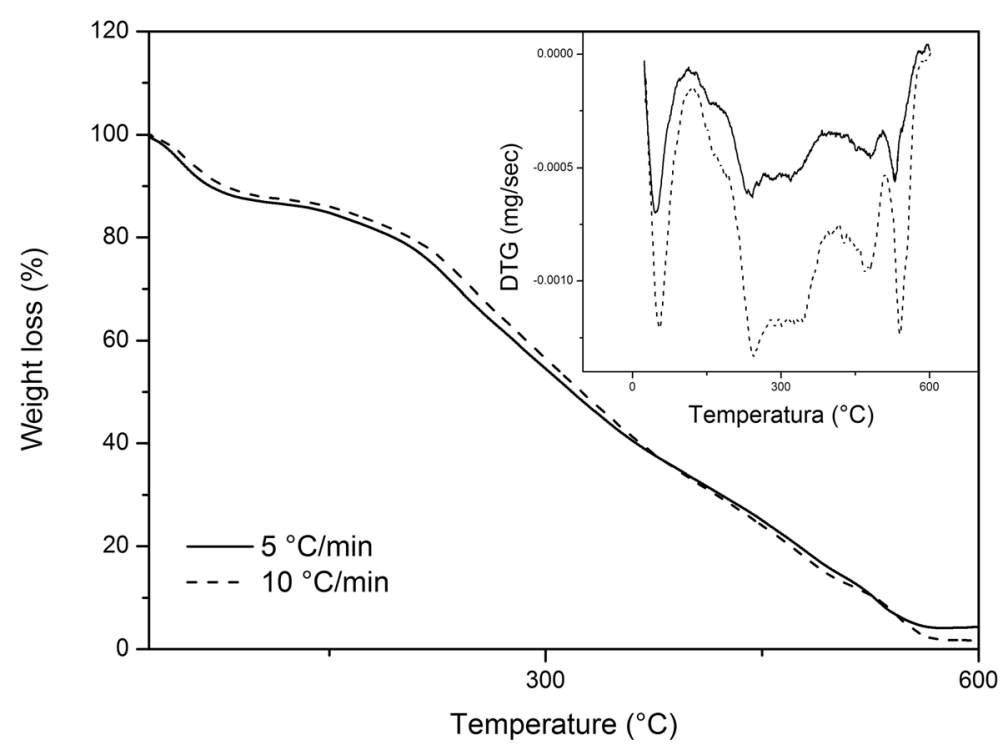

displacement to higher temperatures, as it happens in TG curves. Therefore, DSC peaks found at $10^{\circ} \mathrm{C} / \mathrm{min}$ heating rate were at higher temperatures than those at $5{ }^{\circ} \mathrm{C} / \mathrm{min}$ heating rate.

In the DSC curves of CS-PMAA nanoparticles $0.5 \%$ $(w / v)$ at $5{ }^{\circ} \mathrm{C} / \mathrm{min}$ heating rate, two endotermic and one exotermic events can be found. Both the first one, near $60{ }^{\circ} \mathrm{C}$, and the second one, near $110{ }^{\circ} \mathrm{C}$, correspond to loss of volatile substances such as water. The exothermic event near $400{ }^{\circ} \mathrm{C}$ corresponds to CS-PMAA nanoparticles degradation, probably related to the polymer network decomposition. At $10{ }^{\circ} \mathrm{C} / \mathrm{min}$ heating rate, there was only one endothermic event, near $95{ }^{\circ} \mathrm{C}$, corresponding to loss of volatile substances; and an exothermic event started near $250{ }^{\circ} \mathrm{C}$ with DSC peak above $450^{\circ} \mathrm{C}$ (De Moura et al. 2008).

The change to $10^{\circ} \mathrm{C} / \mathrm{min}$ heating rate showed overlapping endothermic peaks in the first CS-PMAA nanoparticles $0.5 \%(w / v)$ thermal event. The second thermal event, represented by exothermic events corresponding to CS-PMAA nanoparticles $0.5 \%(w / v)$ degradation, was not completely seen in the DSC curve obtained
Fig. 6 CS-PMAA nanoparticles $0.6 \%(w / v)$ TG-DTG curves obtained in $\mathrm{N}_{2}$ atmosphere $(50 \mathrm{~mL} / \mathrm{min})$ and heating rating at 10 and $5^{\circ} \mathrm{C} / \mathrm{min}$

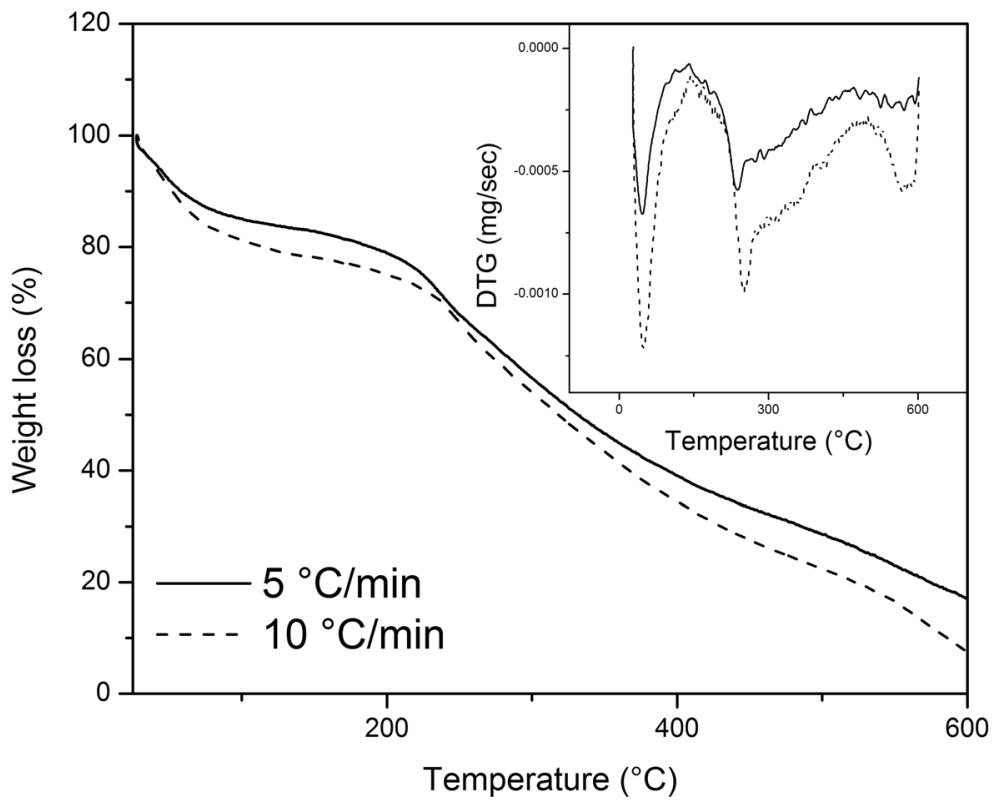


Fig. 7 CS-PMAA nanoparticles $0.7 \%(w / v)$ TG-DTG curves obtained in $\mathrm{N}_{2}$ atmosphere $(50 \mathrm{~mL} / \mathrm{min})$ and heating rating at 10 and $5{ }^{\circ} \mathrm{C} / \mathrm{min}$

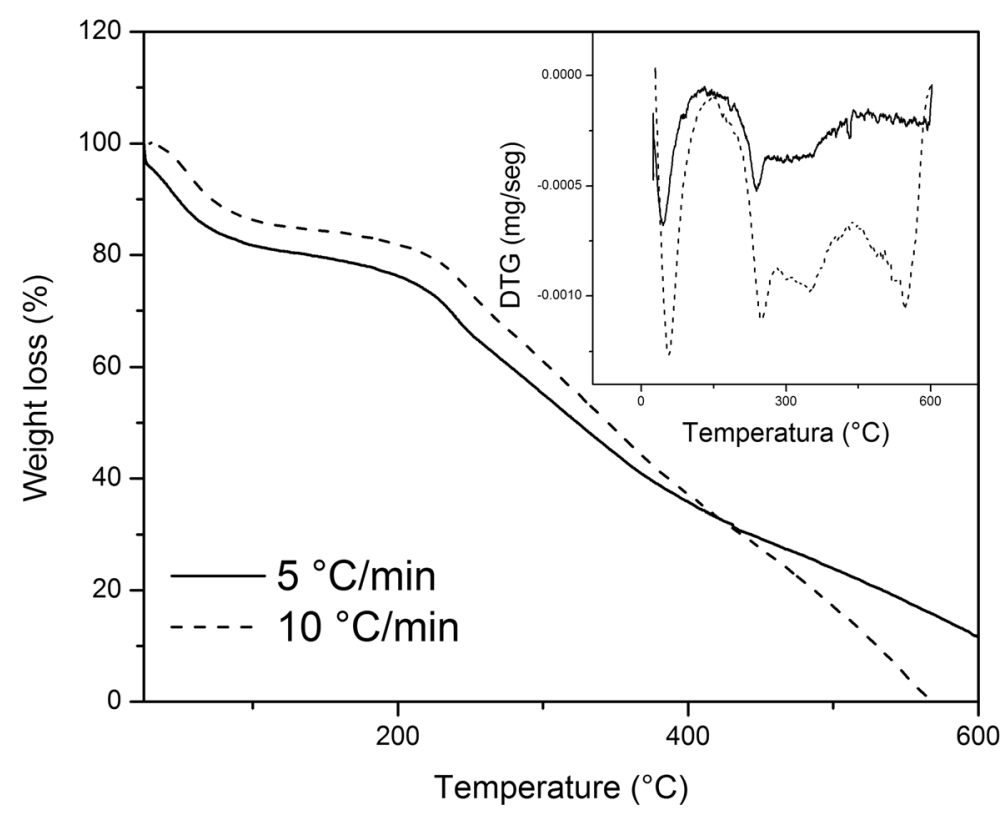

with higher heating rate $\left(10^{\circ} \mathrm{C} / \mathrm{min}\right)$ because, although the curve presented an initial enthalpy change, the peak occurs at temperatures higher than $450{ }^{\circ} \mathrm{C}$.

The comparison of DSC curves between pure $\mathrm{CS}$ and CS-PMAA nanoparticles $0.5 \%(w / v)$ subjected to $10^{\circ} \mathrm{C} /$ min (Fig. 10c) and $5{ }^{\circ} \mathrm{C} / \mathrm{min}$ (Fig. 10d) heating rates does not show an exothermic peak corresponding to CS degradation for CS-PMAA nanoparticles, thus demonstrating the interaction between CS and methacrylic acid during nanoparticles preparation.
CS-PMAA nanoparticles $0.5 \%(w / v)$ did not show any thermal event between the one corresponding to loss of volatile substances and the following exothermic peak corresponding to the decomposition of the material. If present, such additional event could have indicated crystalline behavior or any other phase change (Sreenivasan 1996). The absence of crystalline behavior in DSC curves of CS and CS-PMAA nanoparticles $0.5 \%(w / v)$ indicates that the samples present amorphous character. This feature is very favorable for
Fig. 8 CS-PMAA nanoparticles $0.8 \%(w / v)$ TG-DTG curves obtained in $\mathrm{N}_{2}$ atmosphere $(50 \mathrm{~mL} / \mathrm{min})$ and heating rating at 10 and $5{ }^{\circ} \mathrm{C} / \mathrm{min}$

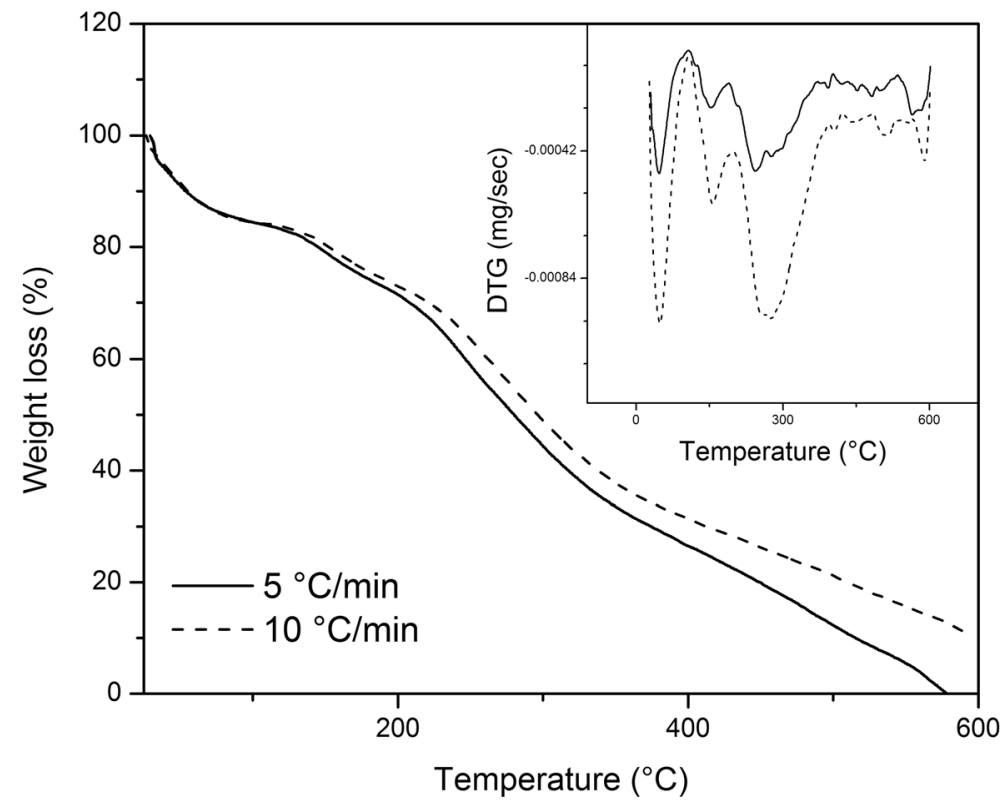


Table 4 Thermal events observed in CS-PMAA nanoparticles TG-DTG curves at 5 and $10{ }^{\circ} \mathrm{C} / \mathrm{min}$ heating rates

\begin{tabular}{|c|c|c|c|c|c|c|c|}
\hline & & \multicolumn{3}{|c|}{ First thermal event } & \multicolumn{3}{|c|}{ Second thermal event } \\
\hline & & Temp. $\left({ }^{\circ} \mathrm{C}\right)$ & Mass loss $(\%)$ & DTG peak $\left({ }^{\circ} \mathrm{C}\right)$ & Temp. $\left({ }^{\circ} \mathrm{C}\right)$ & Mass loss $(\%)$ & DTG peak $\left({ }^{\circ} \mathrm{C}\right)$ \\
\hline \multirow[t]{2}{*}{ CS-PMAA $0.5 \%(w / v)$} & $5^{\circ} \mathrm{C} / \mathrm{min}$ & $25-100$ & 17 & 46 & $130-600$ & 100 & 232 \\
\hline & $10^{\circ} \mathrm{C} / \mathrm{min}$ & $30-120$ & 15 & 54 & $130-600$ & 100 & 239 \\
\hline \multirow[t]{2}{*}{ CS-PMAA $0.6 \%(w / v)$} & $5^{\circ} \mathrm{C} / \mathrm{min}$ & $25-100$ & 14 & 43 & $138-600$ & 84 & 236 \\
\hline & $10^{\circ} \mathrm{C} / \mathrm{min}$ & $30-120$ & 20 & 48 & $144-600$ & 94 & 248 \\
\hline \multirow[t]{2}{*}{ CS-PMAA $0.7 \%(w / v)$} & $5^{\circ} \mathrm{C} / \mathrm{min}$ & $25-120$ & 10 & 44 & $144-600$ & 89 & 240 \\
\hline & $10^{\circ} \mathrm{C} / \mathrm{min}$ & $30-127$ & 15 & 57 & $150-600$ & 100 & 251 \\
\hline \multirow[t]{2}{*}{ CS-PMAA $0.8 \%(w / v)$} & $5^{\circ} \mathrm{C} / \mathrm{min}$ & $25-104$ & 6 & 44 & $110-570$ & 100 & 247 \\
\hline & $10^{\circ} \mathrm{C} / \mathrm{min}$ & $30-107$ & 18 & 47 & $115-600$ & 90 & 270 \\
\hline
\end{tabular}

dissolution and consequently for improving drug bioavailability (Florence and Attwood 2003). Amorphous substances are generally better absorbed than crystalline ones. This statement is based on the energy involved in dissolution process. In amorphous solids, the molecules are arranged randomly and little energy is required to separate them. As a result, dissolution is faster (Corrigan 1995).

The differences found in the area and intensity of water loss in endothermic events between pure CS and
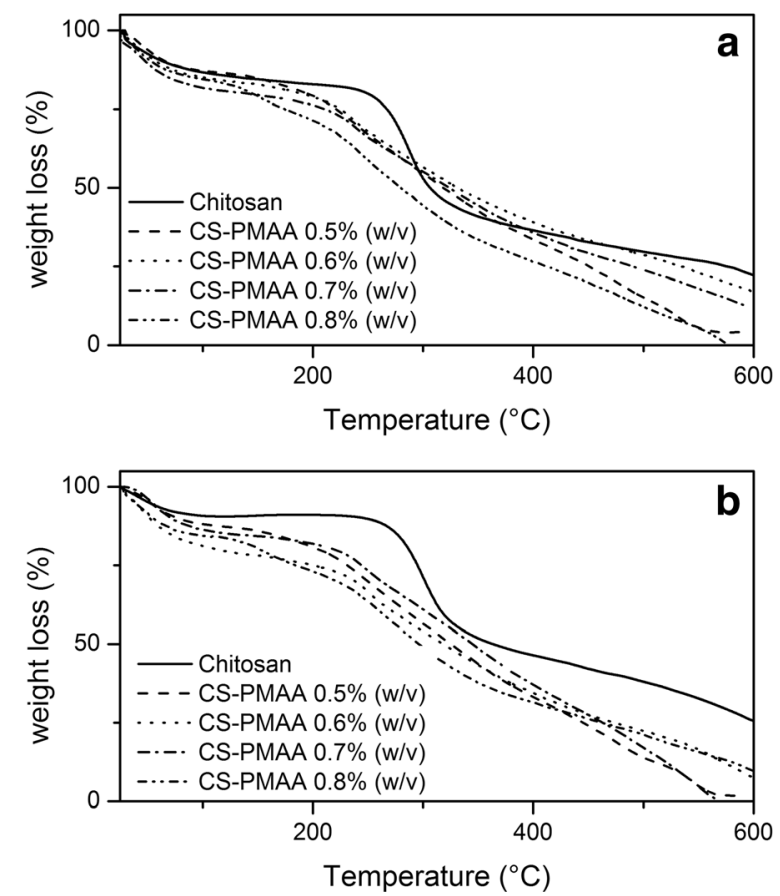

Fig. 9 CS-PMAA nanoparticles and pure CS TG curves obtained in $\mathrm{N}_{2}$ atmosphere $(50 \mathrm{~mL} / \mathrm{min})$ with $5^{\circ} \mathrm{C} / \mathrm{min}$ (a) and $10{ }^{\circ} \mathrm{C} / \mathrm{min}$ (b) heating rates
CS-PMAA nanoparticles $0.5 \%(w / v)$ are related to the samples ability to interact with water molecules. Figure 10c demonstrates that the endothermic event of pure CS is more intense than the one related to the CSPMAA nanoparticles $0.5 \%(w / v)$. This happens because ionic groups present in CS-PMAA nanoparticles are fewer than in pure CS since, during CS-PMAA nanoparticles $0.5 \%(w / v)$ preparation, such ionic groups (amine and hydroxyl) were attached to methacrylic acid ionic groups (carboxyl). Thus, there is a decrease of water-binding sites on CS-PMAA nanoparticles. Figure $10 \mathrm{~d}$ shows that a lower heating rate $\left(5^{\circ} \mathrm{C} / \mathrm{min}\right)$ changes the endotermic event area and peak intensity, with split of the event into two consecutive endotermic events related to water loss from nanoparticles. The first event was related to water attached to amine groups, with weaker bond strength, and the second endotermic event was related to water molecules bonded to hydroxyl groups, which have higher energy and therefore it occurred at higher temperatures (Neto et al. 2005).

Diclofenac sorption on the CS-PMAA nanoparticles

Figure 11 illustrates concentration of diclofenac, after reaching equilibrium, in the solution used to promote its sorption in CS-PMAA nanoparticles. When in equilibrium, $0.5 \mathrm{mg} / \mathrm{mL}$ sodium diclofenac solution presented the following concentrations: $89 \%$ of the initial concentration when in contact with CS-PMAA nanoparticles $0.5 \%(w / v), 88.09 \%$ with CS-PMAA nanoparticles $0.6 \%(w / v), 82.2 \%$ with CS-PMAA nanoparticles $0.7 \%(w / v)$, and $71.84 \%$ with CS-PMAA nanoparticles $0.8 \%(w / v)$. While in $0.8 \mathrm{mg} / \mathrm{mL}$ sodium diclofenac solution, the amount of diclofenac found after 

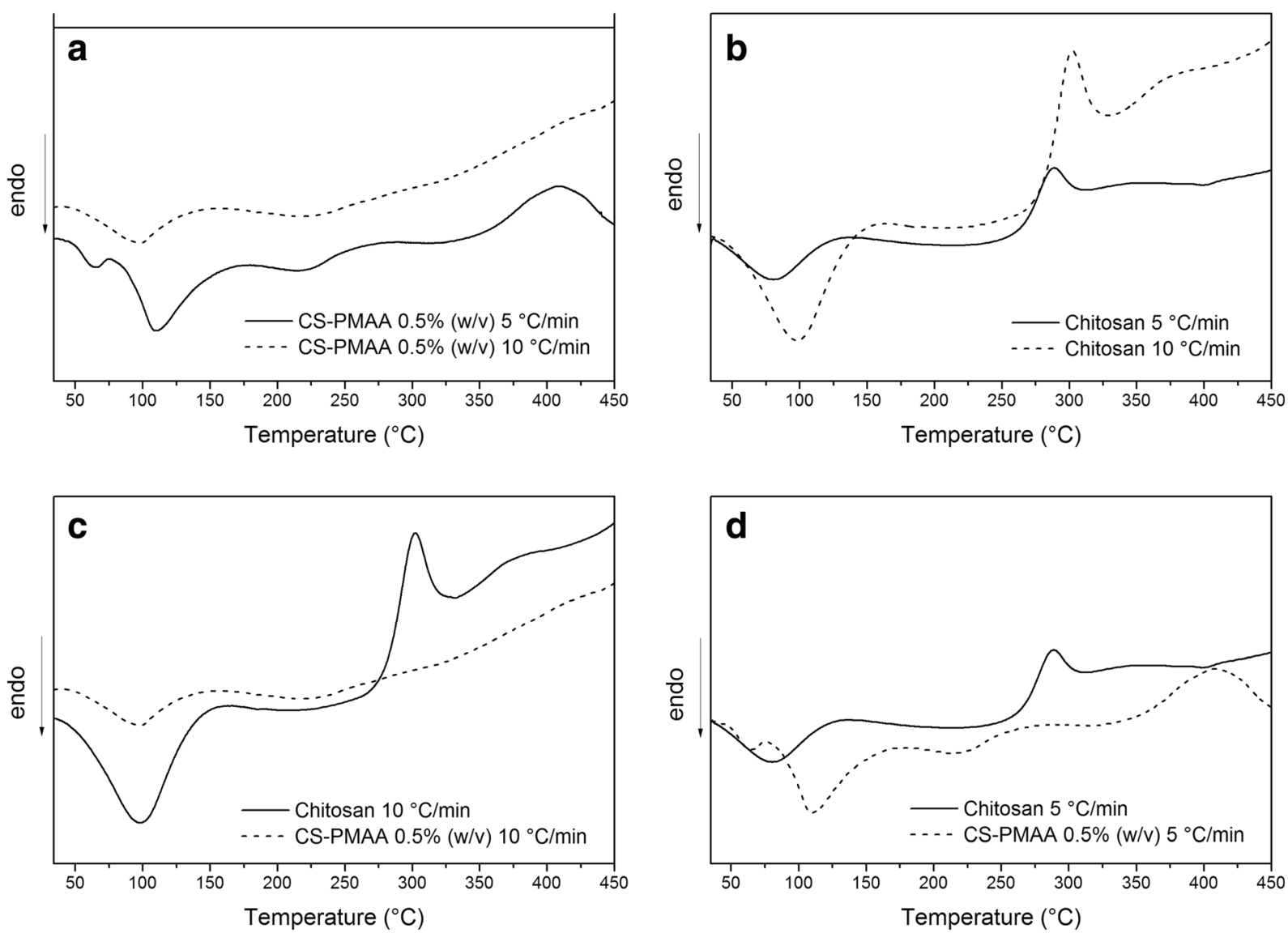

Fig. 10 CS-PMAA nanoparticles $0.5 \%(w / v)$ and pure CS DSC curves obtained in $\mathrm{N}_{2}$ atmosphere $(50 \mathrm{~mL} / \mathrm{min})$ with 5 and $10{ }^{\circ} \mathrm{C} / \mathrm{min}$ heating rates

equilibrium was as follows: $79.13 \%$ of the initial concentration when in contact with CS-PMAA nanoparticles $0.5 \%(w / v) ; 69.01,65.48$, and $58 \%$ when in contact with CS-PMAA nanoparticles $0.6,0.7$, and $0.8 \%(w / v)$, respectively.

Diclofenac sorption efficiency in the CS-PMAA nanoparticles when in contact with different sodium diclofenac solutions $(0.5$ and $0.8 \mathrm{mg} / \mathrm{mL})$ was calculated according to Eq. 1 and the results can be seen in Fig. 12.

The diclofenac amount sorbed per gram of CSPMAA nanoparticles, when in a $0.5 \mathrm{mg} / \mathrm{mL}$ sodium diclofenac solution, was as follows: $12.93 \mathrm{mg} / \mathrm{g}$ for CS-PMAA nanoparticles $0.5 \%(w / v), 15 \mathrm{mg} / \mathrm{g}$ for CSPMAA nanoparticles $0.6 \%(w / v), 20.87 \mathrm{mg} / \mathrm{g}$ for CSPMAA nanoparticles $0.7 \%(w / v)$, and $29.63 \mathrm{mg} / \mathrm{g}$ for CS-PMAA nanoparticles $0.8 \%(w / v)$ CS-PMAA nanoparticles respectively. When a $0.8 \mathrm{mg} / \mathrm{mL}$ sodium diclofenac solution was used, higher sorption efficiencies were obtained: For CS-PMAA nanoparticles $0.5,0.6,0.7$, and $0.8 \%(w / v)$, the sorption efficiencies were $33.39,49.58,55.23$, and $67.2 \mathrm{mg} / \mathrm{g}$, respectively.

Figure 13 makes it possible to predict that better sorption efficiencies should be obtained if increased CS concentrations are used during CS-PMAA nanoparticles preparation.

$\mathrm{CS}$ isoelectric point is at around $\mathrm{pH}$ 6.5. At $\mathrm{pH}$ values below 6.5 , it is positively charged, and this condition favors the association with oppositely charged molecules (Koyano et al. 2000; Du et al. 2006; Popat et al. 2012; Huang et al. 2002). Diclofenac has pKa 4.0. Thus, at $\mathrm{pH} 4$, half of its molecules are in the ionized negatively charged form and half in the nonionized form, So $\mathrm{pH}$ values higher than 4 give more ionized than nonionized molecules (Žilnik et al. 2007). That is, a $\mathrm{pH}$ below about 4 reduces the amount of ionized diclofenac molecules to less than half of the molecules 
Fig. 11 Diclofenac solution concentration decrease when sorption reaches equilibrium

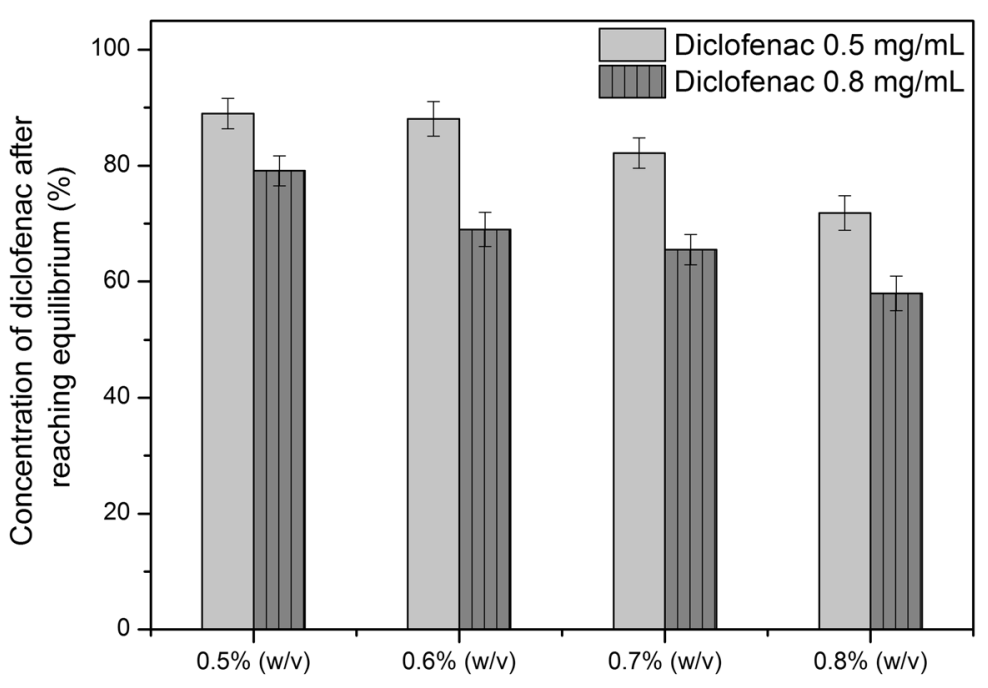

Concentration of chitosan used in the synthesis of nanoparticles present; on the other hand, a $\mathrm{pH}$ above 6.5 decreases the number of CS-PMAA nanoparticles positive charges (De Moura et al. 2008). Thus, the best association efficiency will possibly occur between $\mathrm{pH} 4$ and 6.5 .

The $\mathrm{pH} 5.5$ used in sorption experiment was determined by mathematical modeling, taking into account the diclofenac dissociation constant $(\mathrm{pKa})$ and CSPMAA nanoparticles zeta potential. A relationship between diclofenac $\mathrm{pKa}$ and CS-PMAA nanoparticles zeta potential was evaluated in order to find $\mathrm{pH}$ value in which the best sorption conditions would occur. Ethanol was used because of the low sodium diclofenac water solubility. Various drugs have low water solubility, and the use of solvents other than water is necessary in some cases (Berthold et al. 1996).

The sorption kinetics was monitored at room temperature until reaching equilibrium state. The time to reach diclofenac sorption equilibrium on the CS-PMAA nanoparticles was about $2 \mathrm{~h}$ for all CS-PMAA samples in contact with sodium diclofenac solutions at the initial concentrations of 0.5 and $0.8 \mathrm{mg} / \mathrm{mL}$.

A possible explanation for the short time required for the diclofenac to reach equilibrium could be the combined result of a relatively high diffusivity of diclofenac
Fig. 12 Diclofenac sorption efficiency on the CS-PMAA nanoparticles

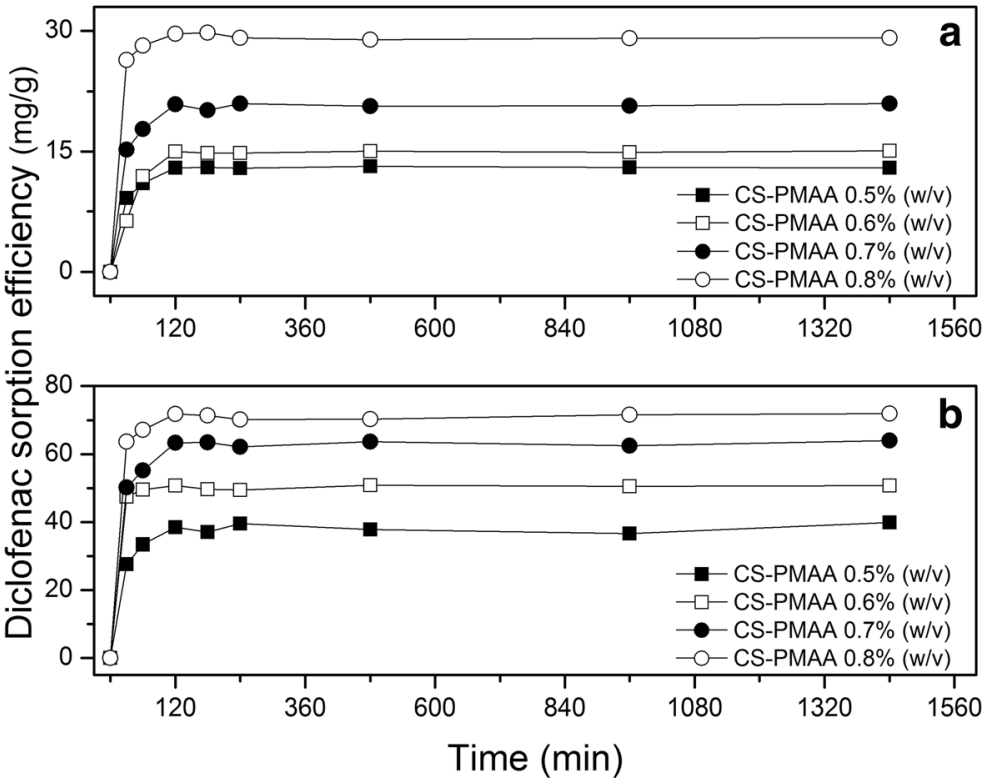


Fig. 13 Relation between CS concentrations used in CS-PMAA nanoparticles preparation and diclofenac sorption efficiency

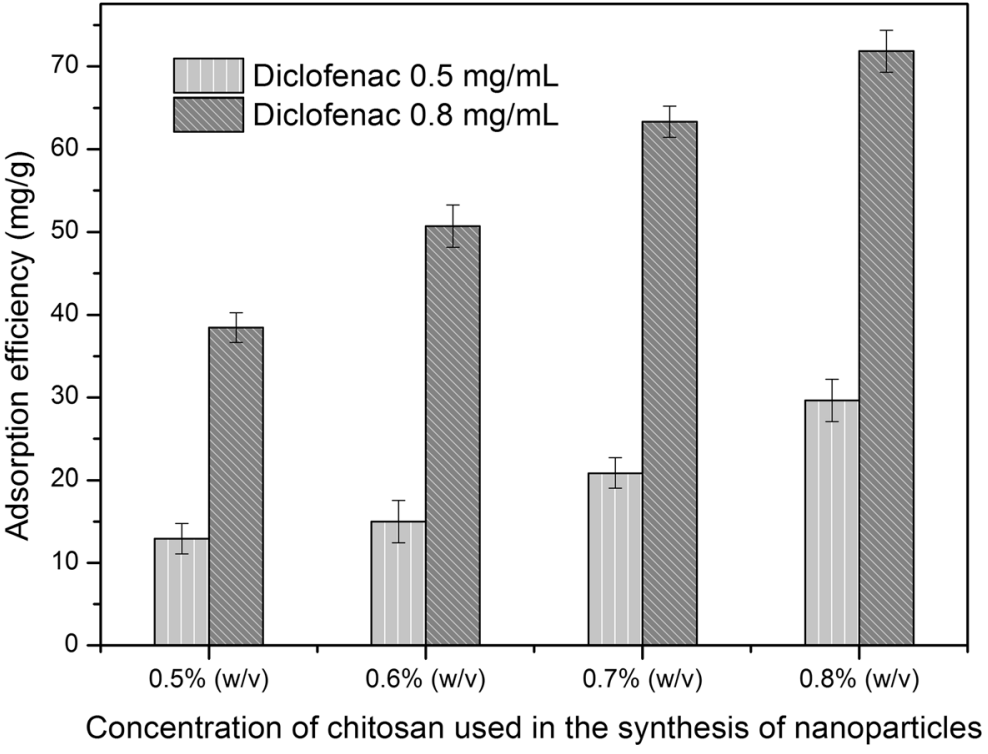

in the nanoparticle matrix and a short radial distance to travel from the surface of the spheroidal-shaped nanoparticle till its center or less. Another possibility is that the association of diclofenac within the bulk matrix is low, and most of the drug associated with the nanoparticles would then be on their surface, which would be rapidly occupied. Because of their little radius, the surface-area-to-volume ratio of these nanoparticles is high, resulting in a high area of adsorption. Finally, perhaps both absorption and adsorption could be happening. Chitosan nanoparticles seem to swell somewhat rapidly in acid solution (Yuan et al. 2010). Hence, the water solution would penetrate the matrix, carrying the diclofenac with it. Some diclofenac would then interact ionically with the chitosan in the bulk matrix, and some with the nanoparticle surface.

In fact, the soaking method has been used to load diclofenac in chitosan (Kumbar et al. 2002). In that method, the association efficiency depends on the swelling of particles in the solution. The swelling decreases with increased cross-linking, resulting in decreased association efficiency (Agnihotri et al. 2004).

The difference between diclofenac amounts found in the initial solution and after reaching equilibrium corresponds to the drug sorbed by the CS-PMAA nanoparticles. As shown in Fig. 11, higher concentrated diclofenac solution promotes better sorption when reaching equilibrium. At a higher diclofenac solution concentration, more diclofenac molecules are available to interact with CS-PMAA nanoparticles amine groups, shifting the chemical equilibrium in the direction that adsorbs some of the additional diclofenac to CS-PMAA nanoparticles. The tiny size of nanoparticles also promotes better sorption results. Increasing CS concentration in CS-PMAA nanoparticles causes a decrease in the particle size obtained (De Moura et al. 2008). The lower size increases the total CS-PMAA nanoparticles superficial contact area, promoting greater interaction with ionized diclofenac molecules and hence increasing sorption. Several factors are responsible for interaction between drug and CS-PMAA nanoparticles, such as $\mathrm{pH}$, contact time, drug concentration, physico-chemical characteristics, and surface area (Schaffazick et al. 2003).

Thermodynamic behavior, including drug solubility, has great importance in pharmaceutical formulation development and optimization. Diclofenac molecule has a Lewis acid-base characteristic due to the presence of heteroatoms $(\mathrm{N}, \mathrm{O}, \mathrm{Cl}, \mathrm{Na})$, which increase its polarity, the $\mathrm{NH}$ group, which acts as an electron donor and acceptor, and the carboxylic acid group $(\mathrm{COOH})$ (Žilnik et al. 2007). Therefore, diclofenac solubility depends on the dissociation constant $(\mathrm{Ka})$ and $\mathrm{pH}$.

Sodium diclofenac solution concentration also causes impact on drug sorption efficiency on the CSPMAA nanoparticles by means of an electrochemical equilibrium. Higher numbers of ionized diclofenac molecules present in the sorption media cause greater reaction displacement to sorption on the CS-PMAA nanoparticles. The interaction between drug and CS-PMAA nanoparticles occurs by electrostatic attraction. In these 
experimental conditions ( $\mathrm{pH}$ 5.5), nanoparticles are positively charged due to the CS molecules with their protonated amino groups, and ionized diclofenac molecules $(\mathrm{pKa}=4)$ have a negative charge represented by the carboxyl group.

A limiting factor for sorption experiments was diclofenac solubility in water/ethanol solution (1:1). The use of other solvents could increase the sodium diclofenac solubility and thus allow one to use more concentrated sodium diclofenac solutions in sorption assays (Žilnik et al. 2007). Diclofenac sorption kinetic models found are shown in Tables 5 and 6 .

According to correlation coefficients obtained by first- and second-order kinetic equations, all sorption reactions follow the pseudo-second-order model. The second-order model reactions occur according to the principle that the sorption capacity is proportional to the number of protonated active sites in the adsorbent molecule and that the chemical interactions between the ions of the adsorbate and adsorbent are the limiting factor for the chemical sorption (Ho and McKay 1999). The second-order kinetics model assumes that two active sites on the adsorbent surface are occupied by each adsorbate ion.

As demonstrated by the second-order kinetic model parameters in Tables 5 and 6, it can be stated that the initial drug concentration was directly related to nanoparticles sorption efficiency. The amount of drug sorbed increased as the initial drug concentration and the chitosan concentration increased (Fig. 12) in all CSPMAAA nanoparticles evaluated.

Diclofenac in vitro release from CS-PMAA nanoparticles

Drug diffusion method through dialysis membrane can determine the drug release profile from CS-PMAA

Table 5 Diclofenac sorption $(0.5 \mathrm{mg} / \mathrm{mL})$ kinetic parameters on the CS-PMAA nanoparticles

\begin{tabular}{llllll}
\hline CS-PMAA & \multicolumn{2}{l}{ First order } & & \multicolumn{2}{l}{ Second order } \\
\cline { 2 - 3 } \cline { 6 - 7 } & $Q_{e}$ & $R^{2}$ & & $Q_{e}$ & $R^{2}$ \\
\hline $0.5 \%(w / v)$ & 0.5073 & 0.3190 & 12.41 & 0.9995 \\
$0.6 \%(w / v)$ & 1.3049 & 0.8883 & 13.38 & 0.9933 \\
$0.7 \%(w / v)$ & 1.4164 & 0.6349 & & 19.88 & 0.9991 \\
$0.8 \%(w / v)$ & 0.9395 & 0.1562 & & 29.05 & 0.9997 \\
\hline
\end{tabular}

Table 6 Diclofenac sorption $(0.8 \mathrm{mg} / \mathrm{mL})$ kinetic parameters on the CS-PMAA nanoparticles

\begin{tabular}{llllll}
\hline \multirow{2}{*}{ CS-PMAA } & \multicolumn{2}{l}{ First order } & & \multicolumn{2}{l}{ Second order } \\
\cline { 2 - 3 } \cline { 6 - 6 } & $Q_{e}$ & $R^{2}$ & & $Q_{e}$ & $R^{2}$ \\
\hline $0.5 \%(w / v)$ & 3.48 & 0.7954 & & 36.75 & 0.9982 \\
$0.6 \%(w / v)$ & 1.44 & 0.8418 & & 49.86 & 0.9997 \\
$0.7 \%(w / v)$ & 2.50 & 0.5039 & & 60.98 & 0.9996 \\
$0.8 \%(w / v)$ & 2.61 & 0.2329 & & 69.86 & 0.9998 \\
\hline
\end{tabular}

nanoparticles. Several studies employ this method for this purpose (Dillen et al. 2004; Hao et al. 2011; Leroueil-Le Verger et al. 1998; Sonaje et al. 2007; Teixeira et al. 2005; Venkatraman et al. 2005; Yoncheva et al. 2003).

Figure 14 shows diclofenac cumulative release profile from CS-PMAA nanoparticles in phosphatebuffered saline ( $\mathrm{pH}$ 7.4) as a function of time up to $48 \mathrm{~h}$. It was observed that CS-PMAA nanoparticles $0.5,0.6$, and $0.7 \%(w / v)$ release kinetics reached $100 \%$ release during the first $24 \mathrm{~h}$. Otherwise, CS-PMAA nanoparticles $0.8 \%(w / v)$ showed release kinetics profile over $48 \mathrm{~h}$.

To determine drug release mechanism from CSPMAA nanoparticles, the Korsmeyer-Peppas model was used, which is a semi-empirical model that correlates drug release as a function of time by a simple exponential equation and that has been used to evaluate drug release from polymeric devices, especially when the drug release mechanism is not known or if more than one mechanism could be involved (Balcerzak and Mucha 2010; Heikkilä et al. 2007; Khandai et al. 2010; Melo et al. 2010). Diclofenac release profile fitted to Korsmeyer-Peppas model can be seen in Fig. 15.

The Korsmeyer-Peppas model variable values found for diclofenac release process from CS-PMAA nanoparticles are shown in Table 7.

According to $r^{2}$ values found, Korsmeyer-Peppas model fits to diclofenac release profile from CSPMAA nanoparticles, considering only the release $<60 \%$ from total. The exponent $n$ indicates release mechanism. Since the nanoparticles were nearly monodispersed, the limiting values of $n$ for these systems are 0.432 and 0.85 . The values in Table 7 are around the value expected for pure diffusion.

There are three phenomena that contribute to drug release from the nanoparticles: gradient concentration, 
Fig. 14 Diclofenac release profile from the CS-PMAA nanoparticles

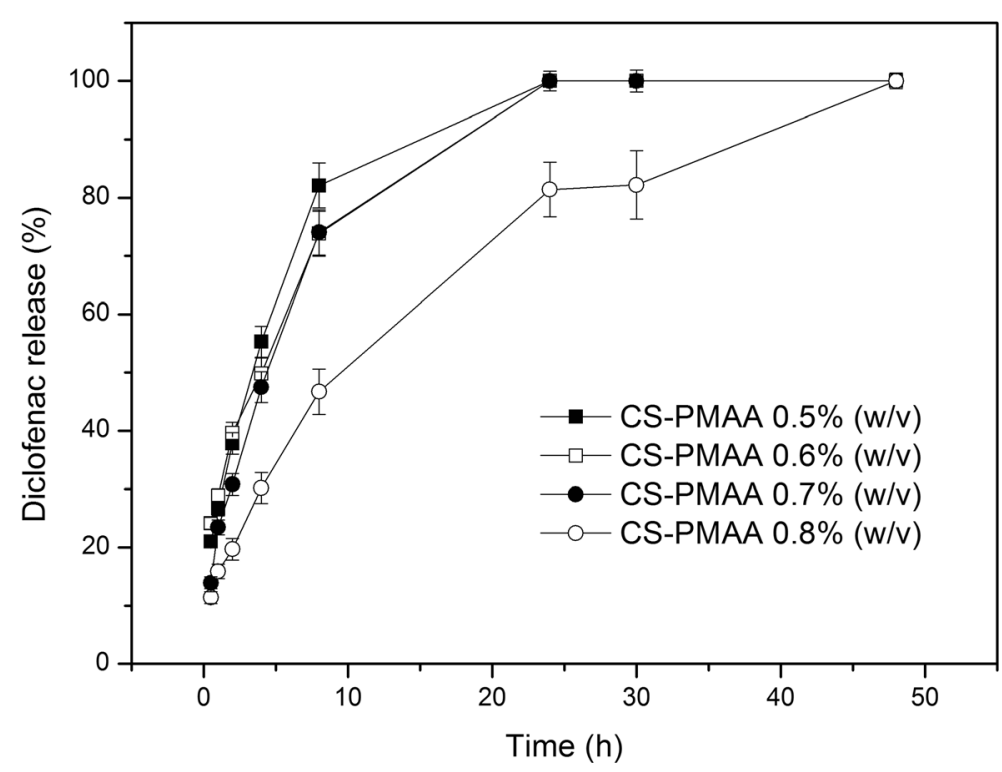

osmotic forces and polymer chains relaxation. When the diffusion rate is much lower than relaxation rate, the diffusion is referred to as case I (Fickian). When the diffusion rate is much higher than relaxation rate, the diffusion is referred to as case II. When diffusion and relaxation rates are comparable, it is called anomalous (Crank 1979).

Most glassy polymers present anomalous release behavior (Crank 1979). Despite that, $n$ was next to the value for Fickian release (Table 7). The variations among the nanoparticles seem to be primarily the result of statistical variation, as described by Sinclair and Peppas (1984). A possible explanation for these $n$ values is the low diffusivity of diclofenac in the matrix when compared to water. Water seems to penetrate the matrix relatively fast (Yuan et al. 2010), leaving room for diclofenac to diffuse out. Diclofenac could be leaving the polymer slower than the water. One reason for this is the larger radius of diclofenac; another reason is because of resistive forces coming from drug-chitosan ionic interactions. Consequently, the diffusion of diclofenac would be slower than the relaxation of the matrix. As a result, a release ruled predominantly by Fickian diffusion could be expected (Crank 1979). In agreement with this, chitosan particles loaded with diclofenac by soaking method presented a release that slightly deviated from the Fickian process (Kumbar et al. 2002). It can be suggested then that the release mechanism was in general slightly anomalous (as expected for glassy polymers), with predomination of Fickian diffusion, possibly because the relaxation rate was somewhat higher than the diclofenac diffusion rate.

\section{Conclusion}

In this study, diclofenac sorption on CS-PMAA nanoparticles and release profiles were assessed. Besides that, CS-PMAA nanoparticles characterization by FTIR, thermal analysis, and transmission electron microscopy were also performed.

CS-PMAA nanoparticles showed good thermal stability. DSC, TG-DTG curves, and FT-IR spectra confirmed CS interaction with methacrylic acid during CSPMAA nanoparticles preparation. TEM images obtained demonstrated that the nanoparticles are spherical and uniform in size.

Drug sorption on CS-PMAA nanoparticles followed a second-order kinetics model and showed itself as promising technique. Drug release from CS-PMAA nanoparticle was prolonged, reaching release time over $48 \mathrm{~h}$, thus confirming that CS-PMAA nanoparticles are promising for modified release systems development.

Acknowledgments All the authors thank the National Council for Scientific and Technological Development $(\mathrm{CNPq})$, Brazilian Federal Agency for Support and Evaluation of Graduate Education (CAPES) and FAPESPA. 

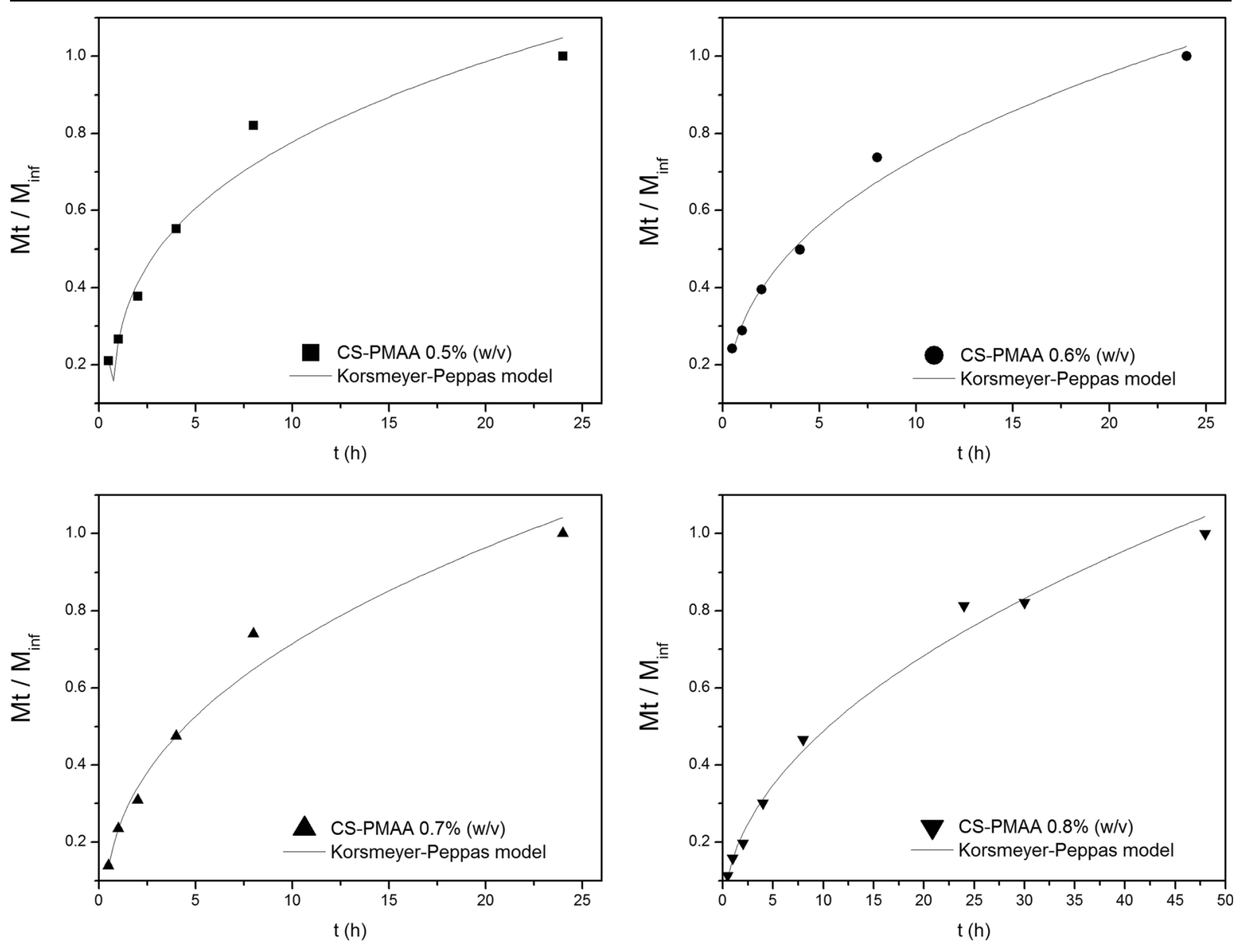

Fig. 15 Diclofenac release according to Korsmeyer-Peppas model

\section{Compliance with ethical standards}

\section{References}

Conflict of interest The authors declare that they have no conflict of interest.

Funding This study was funded by Coordenação de Aperfeiçoamento de Pessoal de Nível Supereior (CAPES) and Fundação Amazônia de Amparo a Estudos e Pesquisa Pará (FAPESPA).

Table 7 Diclofenac release from CS-PMAA nanoparticles kinetic parameters

\begin{tabular}{lll}
\hline CS-PMAA nanoparticles & $n$ & $R^{2}$ \\
\hline $0.5 \%(w / v)$ & 0.47 & 0.9751 \\
$0.6 \%(w / v)$ & 0.36 & 0.9904 \\
$0.7 \%(w / v)$ & 0.57 & 0.9804 \\
$0.8 \%(w / v)$ & 0.50 & 0.9941 \\
\hline
\end{tabular}

Agnihotri SA, Mallikarjuna NN, Aminabhavi TM (2004) Recent advances on chitosan-based micro-and nanoparticles in drug delivery. J Control Release 100(1):5-28

Ahn JS, Choi HK, Cho CS (2001) A novel mucoadhesive polymer prepared by template polymerization of acrylic acid in the presence of chitosan. Biomaterials 22(9):923-928

Akashi M, Ajiro H (2015) Template polymerization (molecular templating). Encycl Polym Nanomater 2498-2502

Azhgozhinova GS, Güven O, Pekel N, Dubolazov AV, Mun GA, Nurkeeva ZS (2004) Complex formation of linear poly (methacrylic acid) with uranyl ions in aqueous solutions. J Colloid Interface Sci 278(1):155-159

Balcerzak J, Mucha M (2010) Analysis of model drug release kinetics from complex matrices of polylactide-chitosan. Progress Chem Appl Chitin Deriv 15:117-125

Bayramoglu G, Denizli A, Bektas S, Arica MY (2002) Entrapment of Lentinus sajor-caju into ca-alginate gel beads for removal of Cd (II) ions from aqueous solution: preparation and biosorption kinetics analysis. Microchem J 72(1):63-76

Berthold A, Cremer K, Kreuter JSTP (1996) Preparation and characterization of chitosan microspheres as drug carrier for 
prednisolone sodium phosphate as model for antiinflammatory drugs. J Control Release 39(1):17-25

Bhumkar DR, Pokharkar VB (2006) Studies on effect of $\mathrm{pH}$ on cross-linking of chitosan with sodium tripolyphosphate: a technical note. AAPS PharmSciTech 7(2):E138-E143

Bratskaya SY, Pestov AV, Yatluk YG, Avramenko VA (2009) Heavy metals removal by flocculation/precipitation using N-(2-carboxyethyl) chitosans. Colloids Surf A Physicochem Eng Asp 339(1):140-144

Cavalheiro ETG, Ionashiro M, Breviglieri ST, Marino G, Chierice GO (1995) A influência de fatores experimentais nos resultados de análises termogravimétricas. Quím Nova 18(3):305-308

Chrissafis K, Bikiaris D (2011) Can nanoparticles really enhance thermal stability of polymers? Part I: an overview on thermal decomposition of addition polymers. Thermochim Acta 523(1):1-24

Corrigan OI (1995) Thermal analysis of spray dried products. Thermochim Acta 248:245-258

Crank J (1979) The mathematics of diffusion. Oxford university press

De Moura MR, Aouada FA, Mattoso LH (2008) Preparation of chitosan nanoparticles using methacrylic acid. J Colloid Interface Sci 321(2):477-483

Dillen K, Vandervoort J, Van den Mooter G, Verheyden L, Ludwig A (2004) Factorial design, physicochemical characterisation and activity of ciprofloxacin-PLGA nanoparticles. Int J Pharm 275(1):171-187

Dos Santos JE, da PSoares J, Dockal ER, Filho SPC, Cavalheiro ÉT (2003) Caracterização de quitosanas comerciais de diferentes origens. Polimeros Cienc Tecnol 13(4):242-249

Du J, Dai J, Liu JL, Dankovich T (2006) Novel pH-sensitive polyelectrolyte carboxymethyl Konjac glucomannanchitosan beads as drug carriers. React Funct Polym 66(10): 1055-1061

Dutta PK, Dutta J, Tripathi VS (2004) Chitin and chitosan: chemistry, properties and applications. J Sci Ind Res 63(1):20-31

Elsabee MZ (2015) Chitosan-based edible films. In Polysaccharides. Springer, pp 829-870

Fang Y, Liu S, Hu D, Cui Y, Xue M (1999) Complexes of chitosan and poly (methacrylic acid) studied by fluorescence techniques. Polym Bull 43(4-5):387-394

Florence AT, Attwood D (2003) Principios fisico quimicos em farmácia

Friederich B, Laachachi A, Ferriol M, Ruch D, Cochez M, Toniazzo V (2010) Tentative links between thermal diffusivity and fire-retardant properties in poly (methyl methacrylate)-metal oxide nanocomposites. Polym Degrad Stab 95(7):1183-1193

Gong M, Li ZF, Wang Q, Sheng KL, Wang XQ, Gong YK (2014) Fabrication of cell outer membrane mimetic surfaces on chitosan nanoparticles by polyionic complex and template polymerization. In applied mechanics and materials (Vol. 618, pp. 335-338). Trans Tech Publ

Hao J, Fang X, Zhou Y, Wang J, Guo F, Li F, Peng X (2011) Development and optimization of solid lipid nanoparticle formulation for ophthalmic delivery of chloramphenicol using a Box-Behnken design. Int J Nanomedicine 6(4): 683-692

Hecq J, Siepmann F, Siepmann J, Amighi K, Goole J (2015) Development and evaluation of chitosan and chitosan derivative nanoparticles containing insulin for oral administration. Drug Dev Ind Pharm 41(12):2037-2044

Heikkilä T, Salonen J, Tuura J, Hamdy MS, Mul G, Kumar N, ..., Hirvonen J (2007) Mesoporous silica material TUD-1 as a drug delivery system. Int J Pharm 331(1):133-138

Hellen KS, Monika PT, Silva MA, Laranjeira MC, de Qualidade LDC (2007) Desenvolvimento, Avaliação e Caracterização Físico Química de Micropartículas Constituídas de Aciclovir/ Quitosana Desenvolvidas pela Técnica de Spray-drying. Lat Am J Pharm 26(6):866-871

Ho YS (2006) Review of second-order models for adsorption systems. J Hazard Mater 136(3):681-689

Ho YS, McKay G (1999) Pseudo-second order model for sorption processes. Process Biochem 34(5):451-465

Hosseini SF, Rezaei M, Zandi M, Farahmandghavi F (2015) Preparation and characterization of chitosan nanoparticlesloaded fish gelatin-based edible films. J Food Process Eng

Hu Y, Jiang X, Ding Y, Ge H, Yuan Y, Yang C (2002) Synthesis and characterization of chitosan-poly (acrylic acid) nanoparticles. Biomaterials 23(15):3193-3201

Hu Y, Chen Y, Chen Q, Zhang L, Jiang X, Yang C (2005) Synthesis and stimuli-responsive properties of chitosan/poly (acrylic acid) hollow nanospheres. Polymer 46(26):12703-12710

Huang H, Hu N, Zeng Y, Zhou G (2002) Electrochemistry and electrocatalysis with heme proteins in chitosan biopolymer films. Anal Biochem 308(1):141-151

Issa MM, Köping-Höggård M, Artursson P (2005) Chitosan and the mucosal delivery of biotechnology drugs. Drug Discov Today Technol 2(1):1-6

Khandai M, Chakraborty S, Sharma A, Pattnaik S, Patra CN, Dinda SC, Sem KK (2010) Preparation and evaluation of algino-sericin mucoadhesive microspheres: an approach for sustained drug delivery. J Adv Pharm Res 1:48-60

Koyano T, Koshizaki N, Umehara H, Nagura M, Minoura N (2000) Surface states of PVA/chitosan blended hydrogels. Polymer 41(12):4461-4465

Kozhunova E, Ji Q, Hill JP, Ariga K (2015) Hollow capsules fabricated by template polymerization of $\mathrm{N}$ Vinylcaprolactam. J Nanosci Nanotechnol 15(3):2389-2393

Kumar MR, Muzzarelli R, Muzzarelli C, Sashiwa H, Domb AJ (2004) Chitosan chemistry and pharmaceutical perspectives. Chem Rev 104(12):6017-6084

Kumbar SG, Kulkarni AR, Aminabhavi TM (2002) Crosslinked chitosan microspheres for encapsulation of diclofenac sodium: effect of crosslinking agent. J Microencapsul 19(2):173-180

Laranjeira MCM, Fávere VD (2009) Quitosana: biopolímero funcional com potencial industrial biomédico. Quím Nova 32(3):672-678

Leroueil-Le Verger M, Fluckiger L, Kim YI, Hoffman M, Maincent P (1998) Preparation and characterization of nanoparticles containing an antihypertensive agent. Eur J Pharm Biopharm 46(2):137-143

Liaw H Jr, Hsueh TY, Tan TS, Wang Y, Chiao SM (2007) Twinscrew compounding of poly (methyl methacrylate)/clay nanocomposites: effects of compounding temperature and matrix molecular weight. Polym Int 56(8):1045-1052

Lima IS, Airoldi C (2004) A thermodynamic investigation on chitosan-divalent cation interactions. Thermochim Acta 421(1):133-139

Luo Y, Teng Z, Li Y, Wang Q (2015) Solid lipid nanoparticles for oral drug delivery: chitosan coating improves stability, 
controlled delivery, mucoadhesion and cellular uptake. Carbohydr Polym 122:221-229

Manjanna KM, Shivakumar B, Pramod kumar T.M. (2009) Diclofenac sodium microbeads for oral sustained drug delivery. Int J PharmTech Res 1(2):317-327

Melo NFSD, Grillo R, Fraceto LF, Dias Filho NL, Paula ED, Araújo DRD, Rosa AH (2010) Desenvolvimento e caracterização de nanocápsulas de poli (L-lactídeo) contendo benzocaína. Quím Nova 65-69

Moldoveanu SC (1998) Analytical pyrolysis of natural organic polymers (Vol. 20). Elsevier

Monteiro OA, Airoldi C (1999) Some thermodynamic data on copper-chitin and copper-chitosan biopolymer interactions. J Colloid Interface Sci 212(2):212-219

Neto CDT, Giacometti JA, Job AE, Ferreira FC, Fonseca JLC, Pereira MR (2005) Thermal analysis of chitosan based networks. Carbohydr Polym 62(2):97-103

Nieto JM, Peniche-Covas C, Padro G (1991) Characterization of chitosan by pyrolysis-mass spectrometry, thermal analysis and differential scanning calorimetry. Thermochim Acta 176:63-68

Paavola A, Yliruusi J, Kajimoto Y, Kalso E, Wahlström T, Rosenberg P (1995) Controlled release of lidocaine from injectable gels and efficacy in rat sciatic nerve block. Pharm Res 12(12):1997-2002

Patil S, Deshmukh V, Renukdas S, Pate N (2011) Kinetics of adsorption of crystal violet from aqueous solutions using different natural materials. Int J Environ Sci 1(6):1116-1134

Piras AM, Maisetta G, Sandreschi S, Gazzarri M, Bartoli C, Grassi L, ..., Batoni G (2015) Chitosan nanoparticles loaded with the antimicrobial peptide temporin B exert a long-term antibacterial activity in vitro against clinical isolates of Staphylococcus epidermidis. Front Microbiol 6:372

Połowiński S (2002) Template polymerisation and co-polymerisation. Prog Polym Sci 27(3):537-577

Popat A, Liu J, Lu GQM, Qiao SZ (2012) A pH-responsive drug delivery system based on chitosan coated mesoporous silica nanoparticles. J Mater Chem 22(22):11173-11178

Poth N, Seiffart V, Gross G, Menzel H, Dempwolf W (2015) Biodegradable chitosan nanoparticle coatings on titanium for the delivery of BMP-2. Biomol Ther 5(1):3-19

Qin C, Li H, Xiao Q, Liu Y, Zhu J, Du Y (2006) Water-solubility of chitosan and its antimicrobial activity. Carbohydr Polym 63(3):367-374

Ritger PL, Peppas NA (1987) A simple equation for description of solute release II. Fickian and anomalous release from swellable devices. J Control Release 5(1):37-42

Sakurai K, Maegawa T, Takahashi T (2000) Glass transition temperature of chitosan and miscibility of chitosan/poly (Nvinyl pyrrolidone) blends. Polymer 41(19):7051-7056

Schaffazick SR, Guterres SS, Freitas LDL, Pohlmann AR (2003) Caracterização e estabilidade físico-química de sistemas poliméricos nanoparticulados para administração de fármacos. Quím Nova 26(5):726-737

Shahidi F, Arachchi JKV, Jeon YJ (1999) Food applications of chitin and chitosans. Trends Food Sci Technol 10(2):37-51

Shigemasa Y, Matsuura H, Sashiwa H, Saimoto H (1996) Evaluation of different absorbance ratios from infrared spectroscopy for analyzing the degree of deacetylation in chitin. Int J Biol Macromol 18(3):237-242
Sinclair GW, Peppas NA (1984) Analysis of non-Fickian transport in polymers using simplified exponential expressions. J Membr Sci 17(3):329-331

Sonaje K, Italia JL, Sharma G, Bhardwaj V, Tikoo K, Kumar MR (2007) Development of biodegradable nanoparticles for oral delivery of ellagic acid and evaluation of their antioxidant efficacy against cyclosporine A-induced nephrotoxicity in rats. Pharm Res 24(5):899-908

Sorrentino A, Gorrasi G, Vittoria V (2007) Potential perspectives of bio-nanocomposites for food packaging applications. Trends Food Sci Technol 18(2):84-95

Sreenivasan K (1996) Thermal stability studies of some chitosanmetal ion complexes using differential scanning calorimetry. Polym Degrad Stab 52(1):85-87

Stoliarov SI, Lyon RE, Nyden MR (2004) A reactive molecular dynamics model of thermal decomposition in polymers. II. Polyisobutylene. Polymer 45(25):8613-8621

Teixeira M, Alonso MJ, Pinto MM, Barbosa CM (2005) Development and characterization of PLGA nanospheres and nanocapsules containing xanthone and 3methoxyxanthone. Eur J Pharm Biopharm 59(3):491-500

Tirkistani FA (1998) Thermal analysis of some chitosan Schiff bases. Polym Degrad Stab 60(1):67-70

Venkatraman SS, Jie P, Min F, Freddy BYC, Leong-Huat G (2005) Micelle-like nanoparticles of PLA-PEG-PLA triblock copolymer as chemotherapeutic carrier. Int J Pharm 298(1):219-232

Wang Y, Zhang Y, Du W, Wu C, Zhao J (2009) Intelligent coreshell nanoparticles and hollow spheres based on gelatin and PAA via template polymerization. J Colloid Interface Sci 334(2):153-160

Wanjun T, Cunxin W, Donghua C (2005) Kinetic studies on the pyrolysis of chitin and chitosan. Polym Degrad Stab 87(3): 389-394

Wen X, Tang L, Qiang L (2014) Stimuli-responsive one-dimensional copolymer nanostructures fabricated by metallogel template polymerization and their adsorption of aspirin. Soft Matter 10(22):3960-3969

Yoncheva K, Vandervoort J, Ludwig A (2003) Influence of process parameters of high-pressure emulsification method on the properties of pilocarpine-loaded nanoparticles. J Microencapsul 20(4):449-458

Younes I, Rinaudo M (2015) Chitin and chitosan preparation from marine sources. Structure, properties and applications. Mar Drugs 13(3):1133-1174

Yu K, Ho J, McCandlish E, Buckley B, Patel R, Li Z, Shapley NC (2013) Copper ion adsorption by chitosan nanoparticles and alginate microparticles for water purification applications. Colloids Surf A Physicochem Eng Asp 425:31-41

Yuan Q, Shah J, Hein S, Misra RDK (2010) Controlled and extended drug release behavior of chitosan-based nanoparticle carrier. Acta Biomater 6(3):1140-1148

Zargar V, Asghari M, Dashti A (2015) A review on chitin and chitosan polymers: structure, chemistry, solubility, derivatives, and applications. ChemBioEng Rev 2(3):204-226

Zhang YW, Chen Y, Zhao JX (2014) Facile fabrication of antibacterial core-shell nanoparticles based on PHMG oligomers and PAA networks via template polymerization. Aust J Chem 67(1):142-150

Žilnik LF, Jazbinšek A, Hvala A, Vrečer F, Klamt A (2007) Solubility of sodium diclofenac in different solvents. Fluid Phase Equilib 261(1):140-145 